\title{
Synthesis of High Molecular Weight Poly(glycerol monomethacrylate) via RAFT Emulsion Polymerization of Isopropylideneglycerol Methacrylate
}

Craig P. Jesson, ${ }^{\dagger}$ Victoria J. Cunningham, ${ }^{\dagger}$ Mark J. Smallridge, ${ }^{\ddagger}$ and Steven P. Armes ${ }^{*} \dagger \oplus$

${ }^{\dagger}$ Department of Chemistry, University of Sheffield, Brook Hill, Sheffield S3 7HF, U.K.

₹GEO Specialty Chemicals, Hythe, Southampton, Hampshire SO45 3ZG, U.K.

Supporting Information

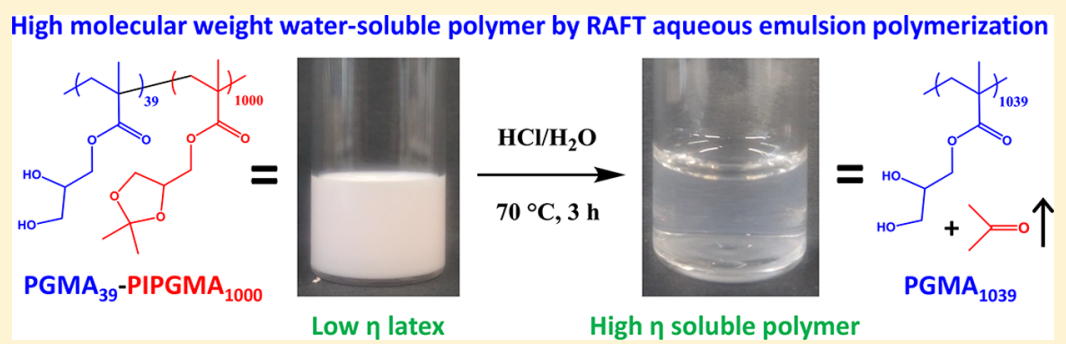

ABSTRACT: High molecular weight water-soluble polymers are widely used as flocculants or thickeners. However, synthesis of such polymers via solution polymerization invariably results in highly viscous fluids, which makes subsequent processing somewhat problematic. Alternatively, such polymers can be prepared as colloidal dispersions; in principle, this is advantageous because the particulate nature of the polymer chains ensures a much lower fluid viscosity. Herein we exemplify the latter approach by reporting the convenient one-pot synthesis of high molecular weight poly(glycerol monomethacrylate) (PGMA) via the reversible addition-fragmentation chain transfer (RAFT) aqueous emulsion polymerization of a water-immiscible protected monomer precursor, isopropylideneglycerol methacrylate (IPGMA) at $70{ }^{\circ} \mathrm{C}$, using a water-soluble poly(glycerol monomethacrylate) (PGMA) chain transfer agent as a steric stabilizer. This formulation produces a low-viscosity aqueous dispersion of PGMA-PIPGMA diblock copolymer nanoparticles at $20 \%$ solids. Subsequent acid deprotection of the hydrophobic core-forming PIPGMA block leads to particle dissolution and affords a viscous aqueous solution comprising high molecular weight PGMA homopolymer chains with a relatively narrow molecular weight distribution. Moreover, it is shown that this latex precursor route offers an important advantage compared to the RAFT aqueous solution polymerization of glycerol monomethacrylate since it provides a significantly faster rate of polymerization (and hence higher monomer conversion) under comparable conditions.

\section{INTRODUCTION}

Water-soluble polymers can be used for a wide range of commercial applications, including as flocculants in brewing, ${ }^{1}$ for dewatering in paper manufacture ${ }^{2-4}$ or for municipal water purification. $^{5-7}$ High molecular weight $\left(>10^{5} \mathrm{~g} \mathrm{~mol}^{-1}\right)$ polymers are particularly efficient and include nonionic, anionic, or cationic polyacrylamides, ${ }^{7-9}$ poly(ethylene oxide) (PEO) ${ }^{10}$ and poly(diallyldimethylammonium) chloride (PDADMAC). ${ }^{11}$ Such polymers induce aggregation via a bridging flocculation mechanism. ${ }^{12-14}$ Water-soluble polymers are also widely employed as viscosity modifiers. ${ }^{15-17}$ For example, $\mathrm{PEO}^{18}$ and poly(acrylic acid) (PAA) ${ }^{19}$ are commonly used as thickening agents in cosmetics, while polyurethanes $(\mathrm{PU})^{20}$ and poly(vinyl alcohol) (PVA) are utilized in paint formulations. ${ }^{21}$ In such applications polymers often confer the additional benefit of acting as steric stabilizers for other components of the formulation, e.g., oil droplets or pigments. ${ }^{22}$

Poly(glycerol monomethacrylate) (PGMA) is a watersoluble polymer that is highly biocompatible and nonfouling and has been utilized for the manufacture of soft contact lenses. ${ }^{23-25}$ Glycerol monomethacrylate (GMA) is a relatively expensive specialty monomer. In principle, it can be obtained via hydrolysis of a cheap commodity monomer, glycidyl methacrylate, in aqueous solution, ${ }^{26}$ but in practice it is actually prepared via a protected precursor, isopropylideneglycerol methacrylate. $^{27}$ In the field of biomaterials, GMA-based copolymers have been used to prepare hydrogels that act as corneal substitutes, ${ }^{28}$ for the design of amphiphilic networks that serve as suitable substrates for dermal fibroblasts, ${ }^{29-31}$ and grown in the form of a hydrophilic brush layer from tissue culture polystyrene in order to improve cell adhesion. ${ }^{32}$ Canton et al. demonstrated that human stem cell colonies enter stasis within $16 \mathrm{~h}$ of their immersion within PGMA-based block copolymer worm gels. ${ }^{33}$ In addition, the cis-diol moiety of

Received: February 7, 2018

Revised: $\quad$ March 27, 2018

Published: April 16, 2018 
PGMA has been utilized for metal binding to magnetite ${ }^{34}$ and other iron-based materials. ${ }^{35}$ Recently, Deng and co-workers reported that 4-aminophenylboronic acid can bind to PGMAbased block copolymer vesicles in alkaline aqueous solution, hence inducing various morphological order-order transitions. $^{36}$

Polymerization-induced self-assembly (PISA) is a wellrecognized and versatile platform technology for the efficient synthesis of a wide range of block copolymer nano-objects. ${ }^{37-44}$ PISA formulations based on RAFT aqueous emulsion polymerization involve chain-extending a water-soluble precursor polymer with a water-immiscible monomer to produce an amphiphilic diblock copolymer in situ. ${ }^{45-56}$ This drives selfassembly to produce sterically stabilized nanoparticles. In principle, the copolymer morphology should simply depend on the relative volume fractions of each block, with more asymmetric blocks forming either worms or vesicles. ${ }^{38,47,57-60}$ However, in many cases only kinetically-trapped spheres are accessible. ${ }^{45,61-67}$ For example, Cunningham and co-workers ${ }^{61}$ explored the scope of RAFT aqueous emulsion polymerization by chain-extending a PGMA macro-CTA with benzyl methacrylate (BzMA) at up to $50 \%$ solids. Only spherical nanoparticles were obtained, but the particle size was readily tunable by varying the DP of the core-forming PBzMA block. A maximum $M_{\mathrm{n}}$ of $117000 \mathrm{~g} \mathrm{~mol}^{-1}$ (measured by DMF GPC vs near-monodisperse PMMA standards) could be achieved when targeting a PBzMA DP of 1000. More recently, Davis and coworkers $^{62}$ have used a similar PISA formulation to produce "ultrahigh" molecular weight polystyrene in the form of a lowviscosity dispersion of sterically stabilized nanoparticles. More specifically, a statistical copolymer of ethylene glycol methyl ether acrylate (EGA) and $N$-hydroxyethyl acrylamide (HEAA) was chain-extended via RAFT aqueous emulsion polymerization of styrene. Block copolymers with $M_{n}$ values exceeding $10^{6} \mathrm{~g} \mathrm{~mol}^{-1}$ were obtained with dispersities of less than 1.40 .

Destarac and co-workers recently reported the synthesis of high molecular weight water-soluble polymers via the RAFT solution polymerization of acrylamide. ${ }^{68} M_{\mathrm{n}}$ values of more than $10^{6} \mathrm{~g} \mathrm{~mol}^{-1}$ with relatively narrow molecular weight distributions (typically $M_{\mathrm{w}} / M_{\mathrm{n}}<1.30$ ) were achieved reproducibly at $10{ }^{\circ} \mathrm{C}$ by utilizing high monomer concentrations and a relatively low initiator concentration. However, the final reaction solutions were relatively viscous. Cunningham and co-workers ${ }^{69}$ offered a potential solution to this problem by utilizing RAFT aqueous dispersion polymerization to prepare a high molecular weight water-soluble polymer above its lower critical solution temperature (LCST). Thus, a PGMA macromolecular chain transfer agent (macro-CTA) was chainextended with $\mathrm{N}$-(2-(methacryloyloxy)ethyl)pyrrolidone (NMEP) at $70{ }^{\circ} \mathrm{C}$ to yield a low-viscosity dispersion of partially hydrated spherical PGMA-PNMEP nanoparticles. PNMEP exhibits an LCST of around $55^{\circ} \mathrm{C}$. Thus, cooling such aqueous dispersions induced particle dissolution to produce molecularly-dissolved copolymer chains at $20{ }^{\circ} \mathrm{C}$, with a concomitant significant increase in solution viscosity. Although not a true homopolymer, the mean degree of polymerization (DP) of the PNMEP block could be systematically varied from 100 up to 4500, which substantially exceeded that of the PGMA stabilizer block. Moreover, DMF GPC analysis indicated relatively low dispersities $\left(M_{\mathrm{w}} / M_{\mathrm{n}}<1.50\right)$, and high NMEP conversions $(>98 \%)$ could be achieved for such PISA formulations. However, literature examples of the preparation of high molecular weight water-soluble homopolymers in low- viscosity form using wholly aqueous formulations are rather rare. $^{70,71}$

Herein we examine such a strategy for the synthesis of high molecular weight PGMA of relatively narrow molecular weight distribution. More specifically, a water-soluble PGMA stabilizer is chain-extended with isopropylideneglycerol methacrylate (IPGMA) using RAFT aqueous emulsion polymerization at $\mathrm{pH} 4$ to produce amphiphilic PGMA-PIPGMA diblock copolymers in the form of sterically stabilized nanoparticles (see Scheme 1). Optimization of this PISA formulation enabled

Scheme 1. Synthesis of PGMA-PIPGMA $\left(\mathrm{G}_{39}-\mathrm{I}_{x}\right)$ Diblock Copolymer Nanoparticles via RAFT Aqueous Emulsion Polymerization of Isopropylideneglycerol Methacrylate (IPGMA) at $70{ }^{\circ} \mathrm{C}$ Using a PGMA Chain Transfer Agent as a Steric Stabilizer

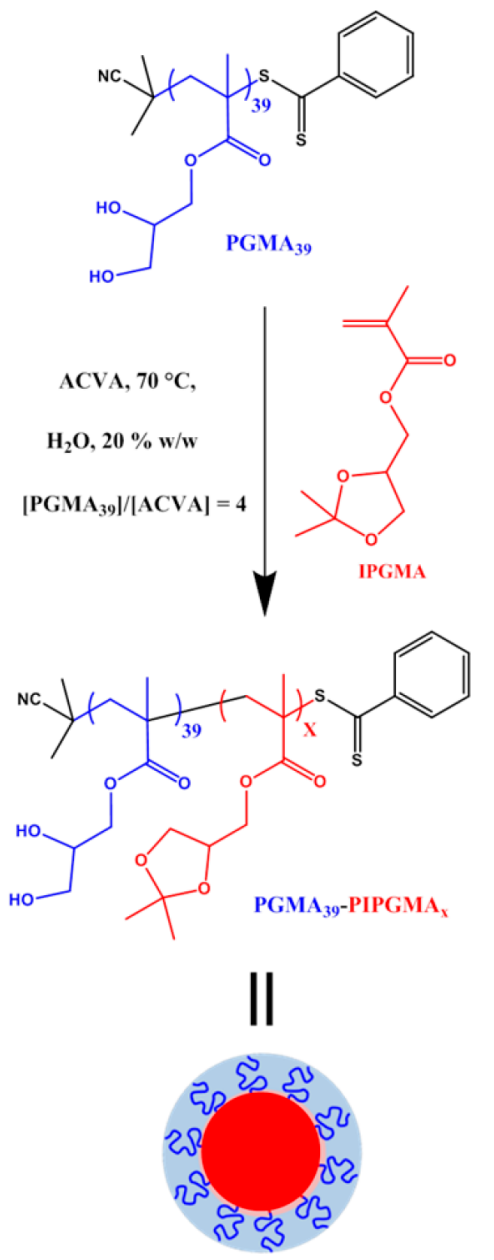

the mean DP to be maximized while achieving at relatively high monomer conversions. Subsequently, the hydrophobic PIPGMA block can be deprotected to afford a water-soluble PGMA homopolymer via selective hydrolysis at low $\mathrm{pH}$. This approach bears some similarity to that employed by Zentel and coworkers, who copolymerized IPGMA to form $\mathrm{pH}$-responsive nanoparticles that undergo dissociation on addition of acid. ${ }^{72}$ In this context, it is also worth noting a recent report by Rimmer and co-workers, who prepared polystyrene-poly(isopropylideneglycerol methacrylate) core-shell latexes via conventional aqueous emulsion polymerization. ${ }^{73}$ Subsequent deprotection of the methacrylic residues in the shell at low $\mathrm{pH}$ 
led to PGMA-stabilized PS latexes that proved to be highly resistant to protein fouling.

\section{EXPERIMENTAL SECTION}

Materials. Glycerol monomethacrylate (GMA, 99.8\%), and isopropylideneglycerol methacrylate (IPGMA, 97.8\%) were donated by GEO Specialty Chemicals (Hythe, UK) and used without further purification. 4,4'-Azobis(4-cyanopentanoic acid) (ACVA, 99\%) and dichloromethane were purchased from Sigma-Aldrich (UK) and were used as received. 2-Cyano-2-propyldithiobenzoate (CPDB) was purchased from Strem Chemicals Ltd. (Cambridge, UK) and was used as received. Deuterated DMF and methanol were purchased from Goss Scientific Instruments Ltd. (Crewe, UK). All other solvents were purchased from Fisher Scientific (Loughborough, UK) and used as received. Deionized water was used for all experiments.

Protocol for the Synthesis of a PGMA Macro-CTA. A PGMA ${ }_{39}$ (or $\mathrm{G}_{39}$ ) macromolecular chain transfer agent (macro-CTA) was synthesized as follows: CPDB RAFT agent $(0.829 \mathrm{~g}, 3.70 \mathrm{mmol})$ and GMA monomer $(30.0 \mathrm{~g}, 187.3 \mathrm{mmol})$ were weighed into a $100 \mathrm{~mL}$ round-bottomed flask and purged under $\mathrm{N}_{2}$ for $30 \mathrm{~min}$. ACVA initiator $(210 \mathrm{mg}, 0.75 \mathrm{mmol}$; CTA/ACVA molar ratio $=5.0)$ and anhydrous ethanol ( $46.6 \mathrm{~mL}$; previously purged with $\mathrm{N}_{2}$ for $30 \mathrm{~min}$ ) were then added, and the resulting red solution was degassed for a further $10 \mathrm{~min}$. The flask was subsequently sealed and immersed into an oil bath set at $70{ }^{\circ} \mathrm{C}$. After $100 \mathrm{~min}$, the GMA polymerization was quenched by exposing the flask to air, immersing it in liquid nitrogen for $30 \mathrm{~s}$, and dilution of the reaction solution with methanol $(100 \mathrm{~mL})$. A final GMA conversion of $69 \%$ was determined by ${ }^{1} \mathrm{H}$ NMR analysis by comparing the integrated monomer vinyl signals at $6.1-6.2 \mathrm{ppm}$ to oxymethylene signals adjacent to the methacrylic ester groups of polymerized GMA residues at 3.8-4.3 ppm (see Figure S1 in the Supporting Information). The methanolic solution was precipitated into a ten-fold excess of dichloromethane. After filtering and washing with dichloromethane, the crude polymer was dissolved in water and the residual dichloromethane was evaporated under vacuum. The resulting aqueous solution was freeze-dried overnight to yield a pink powder. ${ }^{1} \mathrm{H}$ NMR analysis indicated a mean degree of polymerization of $39 \pm 1$ for this purified PGMA macro-CTA, by comparing the integrated aromatic protons assigned to the RAFT CTA end-group at 7.3-8.0 ppm to that of the polymerized GMA repeat units at 3.8-4.3 ppm (see Figure S2). DMF GPC analysis confirmed that this GMA homopolymerization was well-controlled $\left(M_{\mathrm{n}}=11100 \mathrm{~g} \mathrm{~mol}^{-1}, M_{\mathrm{w}} /\right.$ $M_{\mathrm{n}}=1.13$ ).

Preparation of PGMA $_{39}-$ PIPGMA $_{x}$ Nanoparticles via RAFT Aqueous Emulsion Polymerization. PGMA $39-\mathrm{PIPGMA}_{1000}\left(\mathrm{G}_{39^{-}}\right.$ $\mathrm{I}_{1000}$ ) was synthesized as follows: PGMA $_{39}$ macro-CTA (0.026 g, 4.00 $\mu \mathrm{mol})$, IPGMA monomer $(0.80 \mathrm{~g}, 3.99 \mathrm{mmol})$, and ACVA initiator $(0.28 \mathrm{mg}, 1.00 \mu \mathrm{mol})$ were weighed into a $10 \mathrm{~mL}$ round-bottomed flask and dissolved in deionized water $(3.30 \mathrm{~mL})$. The resulting solution was purged under $\mathrm{N}_{2}$ for $30 \mathrm{~min}$ before being sealed and immersed in an oil bath at $70{ }^{\circ} \mathrm{C}$ for $5 \mathrm{~h}$. The polymerization was quenched by exposure to air and cooling to $20^{\circ} \mathrm{C}$. A final IPGMA conversion of more than $97 \%$ was determined by ${ }^{1} \mathrm{H}$ NMR analysis by comparing the integrated monomer vinyl signals at $6.2-6.3 \mathrm{ppm}$ to that of the six methyl protons assigned to the acetal group of the polymerized IPGMA residues at $1.5-1.7 \mathrm{ppm}$ (see Figure S3). These $\mathrm{PGMA}_{39}-\mathrm{PIPGMA}_{1000}$ spherical nanoparticles were used without further purification.

Deprotection of PGMA $_{39}-$ PIPGMA $_{1000}$ Nanoparticles To Afford Water-Soluble PGMA 1039 . A $20 \% \mathrm{w} / \mathrm{w}$ aqueous dispersion of PGMA $_{39}-$ PIPGMA $_{1000}$ diblock copolymer spheres $(4.0 \mathrm{~mL}$; initial $\mathrm{pH}$ 3) was transferred into a $10 \mathrm{~mL}$ round-bottomed flask and adjusted to $\mathrm{pH} 1$ by addition of concentrated $\mathrm{HCl}$. The resulting acidic solution was immersed in an oil bath at $70{ }^{\circ} \mathrm{C}$ for $3 \mathrm{~h} .{ }^{1} \mathrm{H}$ NMR analysis indicated that $99 \%$ of the IPGMA residues were converted into GMA residues, yielding a $16 \% \mathrm{w} / \mathrm{w}$ aqueous acidic solution of water-soluble $\mathrm{PGMA}_{1039}$ homopolymer.

One-Pot Protocol To Afford Water-Soluble PGMA ${ }_{1039}$ via RAFT Aqueous Emulsion Polymerization of IPGMA Followed by Acid Hydrolysis. PGMA $_{39}$ macro-CTA $(0.026 \mathrm{~g}, 4.00 \mu \mathrm{mol})$,
IPGMA monomer $(0.80 \mathrm{~g}, 3.99 \mathrm{mmol})$, and ACVA initiator $(0.28 \mathrm{mg}$, $1.00 \mu \mathrm{mol}$ ) were weighed into a $10 \mathrm{~mL}$ round-bottomed flask and dissolved in deionized water $(3.30 \mathrm{~mL})$. The resulting solution was purged under $\mathrm{N}_{2}$ for 30 min before being sealed and immersed in an oil bath at $70{ }^{\circ} \mathrm{C}$ for $6 \mathrm{~h}$. A final IPGMA conversion of more than $99 \%$ was determined by ${ }^{1} \mathrm{H}$ NMR analysis. The polymerization was quenched by exposure to air. The solution was adjusted to $\mathrm{pH} 1$ by addition of concentrated $\mathrm{HCl}$. The resulting acidic solution was maintained at $70{ }^{\circ} \mathrm{C}$ for $3 \mathrm{~h}$. ${ }^{1} \mathrm{H}$ NMR analysis indicated that $99 \%$ of the IPGMA residues were converted into GMA residues, yielding a $16 \% \mathrm{w} / \mathrm{w}$ aqueous acidic solution of water-soluble $\mathrm{PGMA}_{1039}$ homopolymer.

RAFT Aqueous Solution Polymerization of GMA. CPDB RAFT agent $(11 \mathrm{mg}, 5.00 \mu \mathrm{mol})$ and GMA monomer $(0.80 \mathrm{~g}, 5.00$ mmol; target $\mathrm{DP}=1000$ ) were weighed into a $10 \mathrm{~mL}$ round-bottomed flask and purged under $\mathrm{N}_{2}$ for $30 \mathrm{~min}$. ACVA initiator $(0.35 \mathrm{mg}, 1.25$ $\mu \mathrm{mol}$; CTA/ACVA molar ratio $=4.0)$ was dissolved in deionized water $(3.21 \mathrm{~mL})$ and added to the monomer solution. The resulting solution was purged under $\mathrm{N}_{2}$ for 30 min before sealing the flask and immersing it in an oil bath at $70{ }^{\circ} \mathrm{C}$ for $5 \mathrm{~h}$. The polymerization was quenched by exposure to air and cooling to $20{ }^{\circ} \mathrm{C}$. A final GMA conversion of more than $97 \%$ was determined by ${ }^{1} \mathrm{H}$ NMR analysis.

NMR Spectroscopy. All ${ }^{1} \mathrm{H}$ NMR spectra were recorded in either deuterated methanol (for the PGMA macro-CTAs) or deuterated DMF (for the series of PGMA-PIPGMA diblock copolymers and for monitoring the acid-catalyzed deprotection of the PGMA-PIPGMA diblock precursor to afford PGMA homopolymer) using a $400 \mathrm{MHz}$ Bruker Avance-400 spectrometer (64 scans averaged per spectrum).

Gel Permeation Chromatography (GPC). Copolymer molecular weights and dispersities were determined using an Agilent 1260 Infinity GPC system equipped with both refractive index and UV-vis detectors. Two Agilent PL gel $5 \mu \mathrm{m}$ Mixed-C columns and a guard column were connected in series and maintained at $60{ }^{\circ} \mathrm{C}$. HPLCgrade DMF containing $10 \mathrm{mM} \mathrm{LiBr}$ was used as eluent and the flow rate was set at $1.0 \mathrm{~mL} \mathrm{~min}{ }^{-1}$, with DMSO used as a flow-rate marker. The refractive index detector was used for calculation of molecular weights and dispersities by calibration using a series of ten nearmonodisperse poly(methyl methacrylate) standards (with $M_{\mathrm{n}}$ values ranging from 625 to $618000 \mathrm{~g} \mathrm{~mol}^{-1}$; see Figure S4). UV GPC chromatograms were obtained simultaneously by detection at a fixed wavelength of $309 \mathrm{~nm}$, which corresponds to the absorption maximum for the dithiobenzoate RAFT end-groups.

Transmission Electron Microscopy (TEM). Copolymer dispersions were diluted 50 -fold at $20{ }^{\circ} \mathrm{C}$ to generate $0.20 \% \mathrm{w} / \mathrm{w}$ dispersions. Copper/palladium TEM grids (Agar Scientific, UK) were coated inhouse to produce a thin film of amorphous carbon. These grids were then treated with a plasma glow discharge for $30 \mathrm{~s}$ to create a hydrophilic surface. One droplet of each aqueous diblock copolymer dispersion $(12 \mu \mathrm{L} ; 0.20 \% \mathrm{w} / \mathrm{w})$ was placed on a freshly treated grid for $1 \mathrm{~min}$ and then blotted with filter paper to remove excess solution. To stain the deposited nanoparticles, an aqueous solution of uranyl formate $(9 \mu \mathrm{L} ; 0.75 \% \mathrm{w} / \mathrm{w})$ was placed on the sample-loaded grid via micropipet for $20 \mathrm{~s}$ and then carefully blotted to remove excess stain. Each grid was then carefully dried using a vacuum hose. Imaging was performed using a FEI Tecnai Spirit TEM instrument equipped with a Gatan $1 \mathrm{kMS} 600 \mathrm{CW}$ CCD camera operating at $120 \mathrm{kV}$.

Oscillatory Rheology Experiments. An AR-G2 rheometer equipped with a variable temperature Peltier plate, a $40 \mathrm{~mL} 2^{\circ}$ aluminum cone, and a solvent trap was used for all experiments. Temperature sweeps were conducted at an angular frequency of $1.0 \mathrm{rad} \mathrm{s}^{-1}$ and a constant strain of $1.0 \%$. The temperature was increased by $1.0^{\circ} \mathrm{C}$ between each measurement, allowing an equilibration time of $2 \mathrm{~min}$ in each case. A solvent trap was required to prevent evaporation of water on the time scale of these experiments.

Dynamic Light Scattering (DLS). Measurements were conducted at $25{ }^{\circ} \mathrm{C}$ using a Malvern Instruments Zetasizer Nano series instrument equipped with a $4 \mathrm{~mW} \mathrm{He}-\mathrm{Ne}$ laser $(\lambda=633 \mathrm{~nm})$ and an avalanche photodiode detector. Scattered light was detected at $173^{\circ}$. Copolymer dispersions were diluted to $0.10 \% \mathrm{w} / \mathrm{w}$. Intensity-average hydro- 
dynamic diameters were averaged over three runs and calculated via the Stokes-Einstein equation.

\section{RESULTS AND DISCUSSION}

The goal of this research was to synthesize high molecular weight PGMA homopolymer in aqueous solution via deprotection of PGMA-PIPGMA diblock copolymer nanoparticles, thus circumventing the problem of high solution viscosity usually associated with an aqueous solution polymerization route. ${ }^{68}$ Moreover, given that an emulsion polymerization protocol was employed to prepare the intermediate sterically stabilized nanoparticles, a significantly faster rate of polymerization was anticipated compared to that obtained via aqueous solution polymerization owing to the well-known effect of compartmentalization, which leads to a significant reduction in the rate of termination and hence allows access to high molecular weight polymer chains. ${ }^{74,75}$

Optimization of PGMA-PIPGMA Diblock Copolymer Synthesis. First, a well-defined PGMA macro-CTA $\left(M_{\mathrm{n}}=\right.$ $\left.11100 ; M_{\mathrm{w}} / M_{\mathrm{n}}=1.13\right)$ was prepared at $70{ }^{\circ} \mathrm{C}$ in ethanol using $\mathrm{CPDB}$ as the RAFT CTA. In principle, a trithiocarbonate-based RAFT agent should also be suitable for the RAFT emulsion polymerization of IPGMA. However, a dithiobenzoate-based CTA was chosen for this study in view of the well-controlled RAFT emulsion polymerizations obtained for other waterimmiscible monomers such as benzyl methacrylate or 2,2,2trifluoroethyl methacrylate. ${ }^{61,76}$ The mean DP of this watersoluble homopolymer was determined to be 39 by ${ }^{1} \mathrm{H}$ NMR spectroscopy. Subsequently, this $\mathrm{PGMA}_{39}$ precursor was chainextended via RAFT emulsion polymerization of IPGMA at $20 \%$ $\mathrm{w} / \mathrm{w}$ solids. Like the majority of RAFT aqueous emulsion polymerization formulations, only spherical nanoparticles were obtained using this protocol. ${ }^{40,61,62}$ In the context of the present study, this kinetically-trapped morphology is actually an advantage because it ensures that a relatively low dispersion viscosity is maintained during such syntheses. In each case, high monomer conversions (>97\%) were determined by ${ }^{1} \mathrm{H}$ NMR spectroscopy, as judged by the disappearance of the vinyl proton signals at 5.9 and $6.2 \mathrm{ppm}$. In addition, DMF GPC analysis indicated low dispersities (typically $M_{\mathrm{w}} / M_{\mathrm{n}}<1.29$ ), while DLS studies confirmed the formation of nearmonodisperse spheres (polydispersities typically below 0.10 ). Thus, good control was achieved over both the molecular weight distribution and the particle size distribution during such heterogeneous polymerizations.

The kinetics for the RAFT emulsion polymerization of IPGMA were monitored when targeting a final diblock composition of $\mathrm{PGMA}_{39}-\mathrm{PIPGMA}_{1000}$ by extracting aliquots from the reaction solution at regular time intervals. After quenching the polymerization via dilution and cooling, these samples were analyzed in turn by ${ }^{1} \mathrm{H}$ NMR, DLS, and DMF GPC (see Figures $1 \mathrm{a}, 1 \mathrm{~b}$, and $1 \mathrm{c}$, respectively. ${ }^{1} \mathrm{H}$ NMR spectra recorded at various reaction times (and hence monomer conversions) are shown in Figure S5.

${ }^{1} \mathrm{H}$ NMR studies confirmed that more than $95 \%$ conversion was achieved within $2 \mathrm{~h}$ at $70{ }^{\circ} \mathrm{C}$. DMF GPC analysis indicated the linear evolution of molecular weight with conversion expected for a well-controlled RAFT polymerization, with relatively low dispersities $\left(M_{\mathrm{w}} / M_{\mathrm{n}}<1.40\right)$ being maintained throughout the reaction. Somewhat broader molecular weight distributions were observed above $90 \%$ conversion, as judged by the significant increase in dispersity (from $M_{\mathrm{w}} / M_{\mathrm{n}} \sim 1.23$ up to $M_{\mathrm{w}} / M_{\mathrm{n}} \sim 1.38$ ). This is attributed to chain transfer to (a)
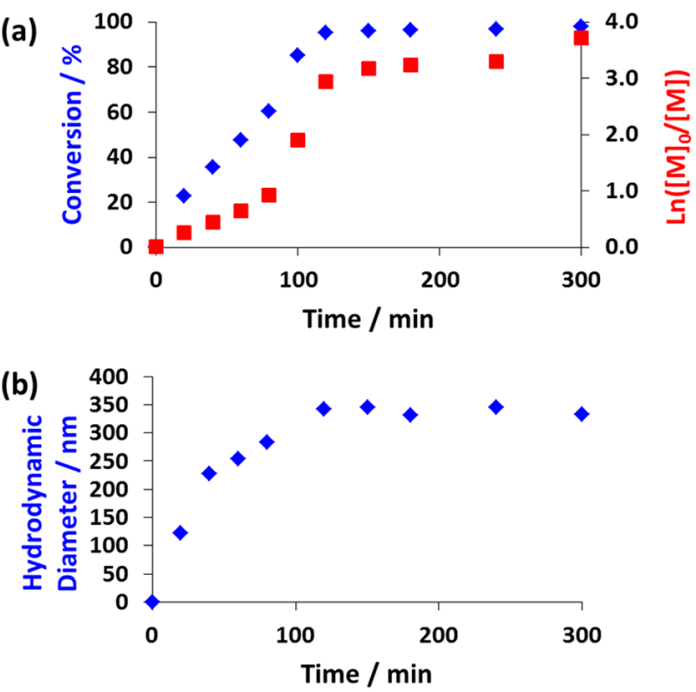

(c)

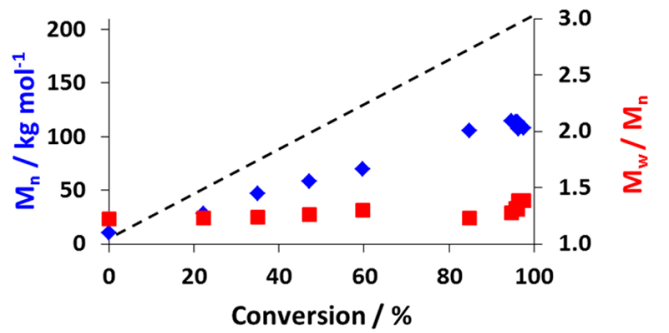

Figure 1. Analysis of aliquots extracted during the PISA synthesis of $\mathrm{PGMA}_{39}-\mathrm{PIPGMA}_{1000}$ nanoparticles via RAFT emulsion polymerization of IPGMA at $70{ }^{\circ} \mathrm{C}$ showing (a) conversion vs time curve and the corresponding semilogarithmic plot against time as determined by ${ }^{1} \mathrm{H}$ NMR spectroscopy, (b) evolution of intensity-average DLS diameter against time, and (c) evolution of $M_{\mathrm{n}}$ and $M_{\mathrm{w}} / M_{\mathrm{n}}$ against conversion determined by DMF GPC using a series of nearmonodisperse poly(methyl methacrylate) calibration standards. The theoretical $M_{\mathrm{n}}$ is shown by a dashed line. Conditions: $20 \% \mathrm{w} / \mathrm{w}$ solids; ACVA initiator; macro-CTA/ACVA molar ratio $=4.0$.

polymer, which becomes more likely under monomer-starved conditions. Close inspection of the semilogarithmic plot revealed a significant rate acceleration between 90 and 120 min. In the case of RAFT dispersion polymerization formulations, such data have been interpreted in terms of the onset of micellar nucleation. ${ }^{77-81}$ However, the concomitant DLS studies indicate the presence of (presumably) monomerswollen nanoparticles of around $120 \mathrm{~nm}$ in the reaction solution after just $20 \mathrm{~min}$ (which corresponds to the time at which the first aliquot was extracted). Such early nucleation is not atypical for RAFT emulsion polymerization syntheses. ${ }^{61,82}$ For the present formulation it is also physically realistic because the monomer conversion observed after $20 \mathrm{~min}$ is approximately $22 \%$, which corresponds to a mean DP of 220 for the hydrophobic PIPGMA block. Between 80 and $100 \mathrm{~min}$ there is a discernible increase in the rate of IPGMA polymerization. There are only a few literature examples of PISA formulations exhibiting faster polymerization kinetics after the onset of micellar nucleation. ${ }^{80,83,84}$ This unusual behavior is not fully understood, but it is worth emphasizing that we have observed such behavior for both aqueous and nonaqueous PISA systems.

In a second set of experiments, a series of $\mathrm{PGMA}_{39}$ PIPGMA $_{x}$ diblock copolymers were prepared by targeting PIPGMA DPs ranging between 100 and 2000 while maintaining an overall solids concentration of $20 \% \mathrm{w} / \mathrm{w}$. 
Given that the PGMA macro-CTA/initiator molar ratio was fixed at 4 , this means that lower initiator concentrations are utilized when targeting higher DPs. This leads to progressively slower RAFT polymerizations, and at some point the radical flux becomes so low that the final monomer conversion becomes rather irreproducible for such formulations. ${ }^{69}$ Indeed, high IPGMA conversions (at least 97\%) could be achieved when targeting DPs up to 1000 , with narrow molecular weight distributions being maintained (see Table 1). However, a

Table 1. Summary of Monomer Conversion, Molecular Weight, and Intensity-Average Particle Diameter Data Obtained Using ${ }^{1} \mathrm{H}$ NMR Spectroscopy, DMF GPC (Refractive Index Detector; Poly(methyl methacrylate) Standards), and Dynamic Light Scattering (DLS), Respectively, for a Series of PGMA PG $_{39}-$ PIPGMA $_{\mathrm{X}}\left(\mathrm{G}_{39}-\mathrm{I}_{x}\right)$ Diblock Copolymer Nanoparticles Prepared at 20\% w/w Solids via RAFT Aqueous Emulsion Polymerization of IPGMA at $70{ }^{\circ} \mathrm{C}$

\begin{tabular}{|c|c|c|c|c|c|}
\hline $\begin{array}{l}\text { sample } \\
\text { no. }\end{array}$ & $\begin{array}{c}\text { target } \\
\text { composition }\end{array}$ & $\begin{array}{c}\text { conv } \\
(\%)\end{array}$ & $\begin{array}{l}\mathrm{GPC} M_{\mathrm{n}} \\
\left(\mathrm{g} \mathrm{mol}^{-1}\right)\end{array}$ & $M_{\mathrm{w}} / M_{\mathrm{n}}$ & $\begin{array}{c}\text { diameter/ } \\
n m\end{array}$ \\
\hline 1 & $\mathrm{G}_{39}$ & 69 & 11100 & 1.13 & N/A \\
\hline 2 & $\mathrm{G}_{39}-\mathrm{I}_{100}$ & 99 & 21500 & 1.24 & 42 \\
\hline 3 & $\mathrm{G}_{39}-\mathrm{I}_{200}$ & 99 & 30500 & 1.26 & 66 \\
\hline 4 & $\mathrm{G}_{39}-\mathrm{I}_{300}$ & 99 & 42100 & 1.29 & 98 \\
\hline 5 & $\mathrm{G}_{39}-\mathrm{I}_{400}$ & 99 & 51800 & 1.23 & 132 \\
\hline 6 & $\mathrm{G}_{39}-\mathrm{I}_{500}$ & 99 & 61500 & 1.21 & 163 \\
\hline 7 & $\mathrm{G}_{39}-\mathrm{I}_{600}$ & 99 & 71900 & 1.22 & 207 \\
\hline 8 & $\mathrm{G}_{39}-\mathrm{I}_{700}$ & 98 & 86400 & 1.28 & 247 \\
\hline 9 & $\mathrm{G}_{39}-\mathrm{I}_{800}$ & 97 & 90000 & 1.28 & 297 \\
\hline 10 & $\mathrm{G}_{39}-\mathrm{I}_{900}$ & 97 & 99200 & 1.22 & 315 \\
\hline 11 & $\mathrm{G}_{39}-\mathrm{I}_{1000}$ & 97 & 125000 & 1.20 & 363 \\
\hline $12^{a}$ & $\mathrm{G}_{39}-\mathrm{I}_{1500}$ & 95 & 159500 & 1.32 & 717 \\
\hline 13 & $\mathrm{G}_{39}-\mathrm{I}_{2000}$ & 42 & 96200 & 1.16 & 1172 \\
\hline
\end{tabular}

${ }^{a}$ Attempts to reproduce this formulation led to significantly lower monomer conversions.

substantially lower conversion (42\%) was obtained when targeting a DP of 2000. For an intermediate target DP of 1500 , a final IPGMA conversion of $95 \%$ was achieved in one particular synthesis, but several attempts to repeat this result were unsuccessful (Table 1 contains details of the best results achieved for this PISA formulation, which is on the cusp of irreproducibility owing to the relatively low initiator concentration). Thus, high conversions could only be reproducibly achieved when targeting DPs of up to 1000 . For this upper limit DP the $M_{\mathrm{w}} / M_{\mathrm{n}}$ was 1.20 , which indicates relatively good RAFT control. ${ }^{85-87}$

DMF GPC analysis of the first eleven samples shown in Table 1 revealed a linear evolution in $M_{\mathrm{n}}$ with increasing PIPGMA block DP (see Figure 2a), which is similar to that previously observed for the RAFT aqueous dispersion polymerization of NMEP. ${ }^{69}$ Moreover, DLS studies indicated a linear correlation between the intensity-average diameter and PIPGMA DP for this series of spherical nanoparticles (see Figure 2b). Cunningham and co-workers also reported a monotonic increase in particle size with core-forming block DP for the synthesis of PGMA-PBzMA diblock copolymer nanoparticles prepared via RAFT emulsion polymerization. However, the mean hydrodynamic sphere diameters obtained in this earlier work were much smaller than those observed in the current study for similar core-forming block DPs. ${ }^{61}$ Unlike
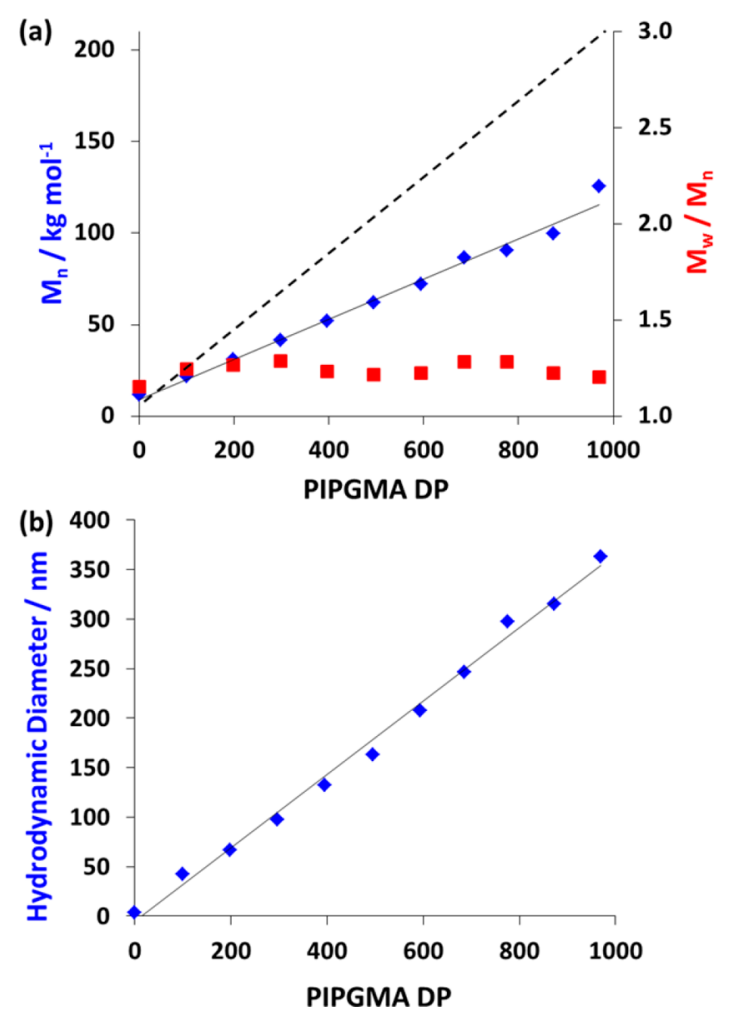

Figure 2. (a) Evolution of $M_{\mathrm{n}}$ and $M_{\mathrm{w}} / M_{\mathrm{n}}$ with PIPGMA DP, where the theoretical $M_{n}$ is shown by a dashed line. (b) Correlation between intensity-average DLS diameter against PIPGMA DP for a series of $\mathrm{PGMA}_{39}-\mathrm{PIPGMA}_{x}$ spherical nanoparticles prepared via RAFT aqueous emulsion polymerization of IPGMA at $70^{\circ} \mathrm{C}$ (see Table 1).

the PNMEP-core particles reported by Cunningham et al., ${ }^{69}$ it seems unlikely that the PIPGMA-core particles are appreciably hydrated. However, we cannot rule out the possibility that some degree of deprotection of the IPGMA residues occurs in situ during the RAFT aqueous emulsion polymerization. If this were the case, it would introduce hydrophilic GMA units within the core-forming block, which could lead to some degree of particle swelling. However, such GMA units in the coreforming block would be spectroscopically indistinguishable from those in the stabilizer block.

Transmission electron microscopy images obtained for the PGMA $_{39}-$ PIPGMA $_{1000}$ diblock copolymer nanoparticles (see entry 11, Table 1) are shown in Figure 3. This confirms the well-defined spherical morphology for such nanoparticles.

Systematic Variation of the Copolymer Concentration. PIPGMA DPs of 1000, 1500, and 2000 were targeted in turn at $30 \% \mathrm{w} / \mathrm{w}$ solids using $\mathrm{PGMA}_{39}$ as the steric stabilizer block. However, such formulations only led to the formation of thick pastes, rather than free-flowing colloidal dispersions. Similar results were obtained at $25 \% \mathrm{w} / \mathrm{w}$ solids. Empirically, it was found that free-flowing dispersions could only be obtained at $20 \% \mathrm{w} / \mathrm{w}$ copolymer concentration when targeting PIPGMA DPs of 1000 . Attempts to confer greater steric stabilization by utilizing a $\mathrm{PGMA}_{63}$ macro-CTA at $20 \% \mathrm{w} / \mathrm{w}$ solids also proved to be unsuccessful when targeting DPs of 1500 or 2000: freeflowing dispersions were obtained under such conditions, but conversions proved to be substantially incomplete. Using a lowtemperature initiator (2,2'-azobis [2-(2-imidazolin-2-yl)propane]dihydrochloride; VA-044) at $50{ }^{\circ} \mathrm{C}$ combined with this longer stabilizer block enabled a final conversion of $84 \%$ to 


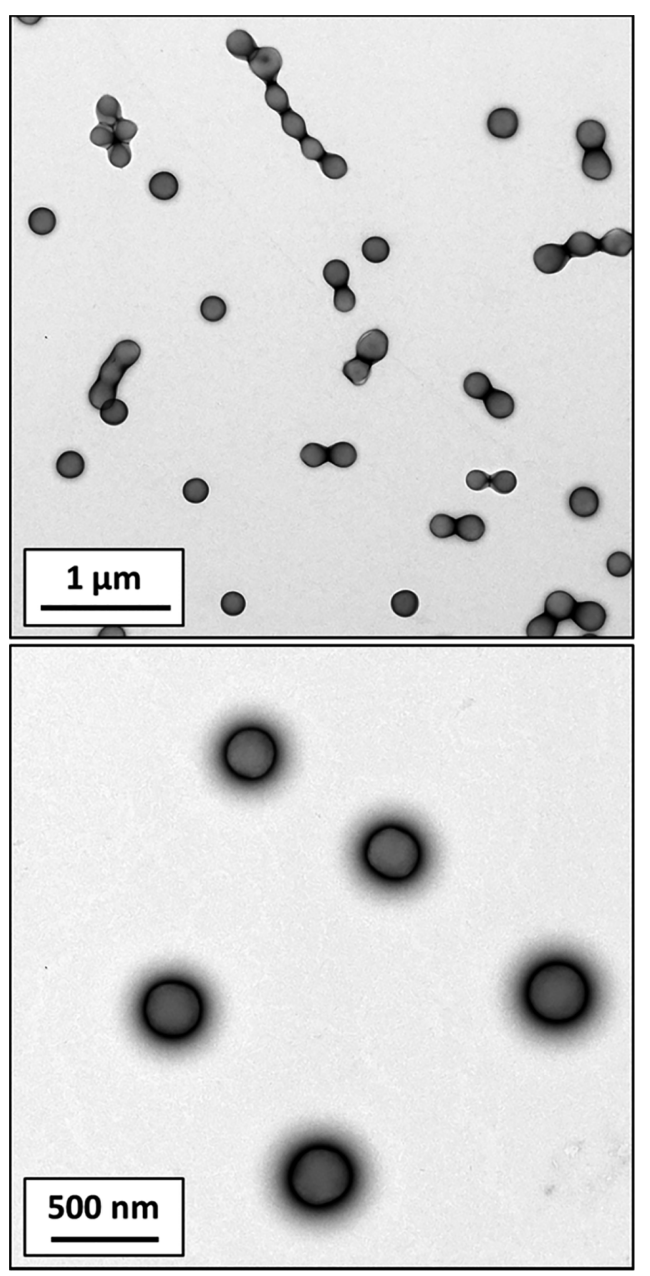

Figure 3. Representative TEM images obtained for the $\mathrm{PGMA}_{39}-$ PIPGMA $_{1000}$ diblock copolymer nanoparticles.

be achieved when targeting a DP of 2000. DMF GPC analysis of this PGMA $_{39}-$ PIPGMA $_{1680}$ copolymer indicated an $M_{n}$ of 203000 but a relatively broad molecular weight distribution
$\left(M_{\mathrm{w}} / M_{\mathrm{n}}=1.65\right)$, which suggests significant loss of RAFT control under such conditions. In summary, the optimal conditions for the RAFT aqueous emulsion polymerization of IPGMA at $70{ }^{\circ} \mathrm{C}$ involves using the $\mathrm{PGMA}_{39}$ macro-CTA at $20 \% \mathrm{w} / \mathrm{w}$ solids. This formulation reproducibly affords a final conversion of at least $97 \%$ within $2 \mathrm{~h}$ when targeting a DP of 1000 , which produces an apparent $M_{\mathrm{n}}$ of around $125000 \mathrm{~g}$ $\mathrm{mol}^{-1}$ and an $M_{\mathrm{w}} / M_{\mathrm{n}}$ of 1.20-1.37 (e.g., see entry 11 in Table $1)$.

Deprotection of PGMA-PIPGMA Spheres. It is wellknown that acetal protecting groups are readily removed on addition of aqueous acid. ${ }^{8}$ Indeed, the industrial manufacture of GMA monomer is achieved via acid-catalyzed deprotection of IPGMA, ${ }^{27}$ and Hoogeveen et al. reported the preparation of PGMA-based diblock copolymers from PIPGMA-based precursors via acid hydrolysis at ambient temperature for $72 \mathrm{~h} .{ }^{89}$ Very recently, Russell and co-workers reported the deprotection of IPGMA residues in a series of polystyrene-PIPGMA (PS-PIPGMA) diblock copolymers using $\mathrm{HCl}$ in 1,4dioxane. $^{90}$ Of particular relevance to the present study, a similar strategy was recently utilized by Rimmer and co-workers for the synthesis of sterically stabilized PS-PGMA latexes from precursor core-shell PS-PIPGMA particles. ${ }^{73}$ In this case, acid hydrolysis was conducted in aqueous solution at approximately $\mathrm{pH} 1$ for $4-8 \mathrm{~h}$ at $60{ }^{\circ} \mathrm{C}$, but no kinetic studies of the extent of deprotection were reported.

Initial deprotection experiments involved adjusting the solution $\mathrm{pH}$ of a $20 \% \mathrm{w} / \mathrm{w}$ aqueous dispersion of $\mathrm{PGMA}_{39}-$ PIPGMA $_{1000}$ nanoparticles to $\mathrm{pH} 1$ via addition of $\mathrm{HCl}$. This acidified turbid dispersion was then stirred for several days at 20 ${ }^{\circ} \mathrm{C}$, but there was no discernible change in its appearance. In principle, successful deprotection of the acetal groups on the hydrophobic PIPGMA block should result in nanoparticle dissolution to form a transparent solution because the resulting PGMA homopolymer is water-soluble. This transformation was subsequently achieved for the same copolymer formulation by heating to $70{ }^{\circ} \mathrm{C}$ at $\mathrm{pH} 1$. It is perhaps worth noting that the volatile acetone byproduct (bp $56{ }^{\circ} \mathrm{C}$ ) is removed from the reaction solution at this temperature, which helps to drive the

(a)

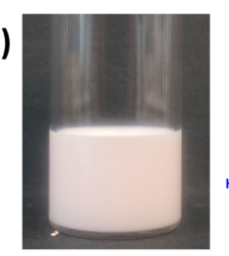<smiles>CC(C)CCCCCCCCCCCC(C)(C)C(=O)OCC1COC(C)(C)O1</smiles>

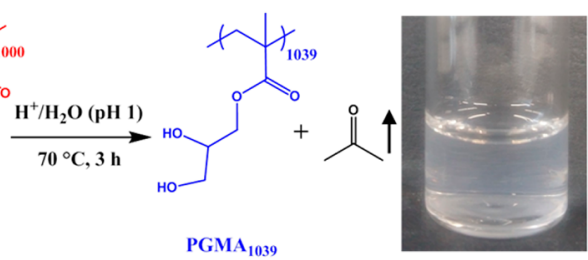

(b)

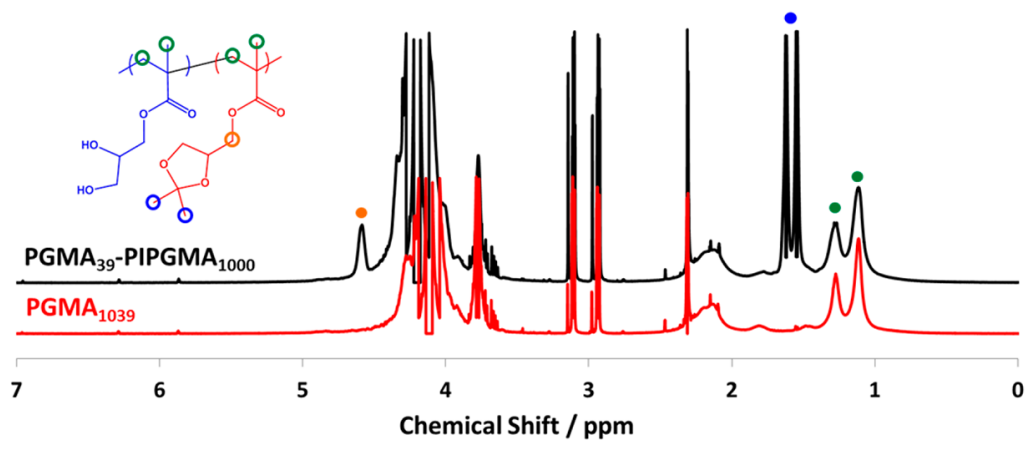

Figure 4. (a) Reaction scheme for the acid-catalyzed deprotection of $\mathrm{PGMA}_{39}-\mathrm{PIPGMA}_{1000}$ nanoparticles at $70{ }^{\circ} \mathrm{C}$ to afford water-soluble $\mathrm{PGMA}_{1039}$ chains after $3 \mathrm{~h}$ at $\mathrm{pH}$ 1. (b) ${ }^{1} \mathrm{H}$ NMR spectra in $d_{7}$-DMF recorded for the initial $\mathrm{PGMA}_{39}-\mathrm{PIPGMA}_{1000}$ nanoparticles and the final watersoluble $\mathrm{PGMA}_{1039}$ homopolymer obtained as a result of this acid-catalyzed deprotection. 
reaction toward completion. The extent of acetal deprotection under such conditions was monitored by extracting aliquots from the reaction dispersion/solution at predetermined time intervals for analysis by ${ }^{1} \mathrm{H}$ NMR spectroscopy (in $d_{7}$-DMF), DMF GPC, and DLS (see Figures 4 and 5).

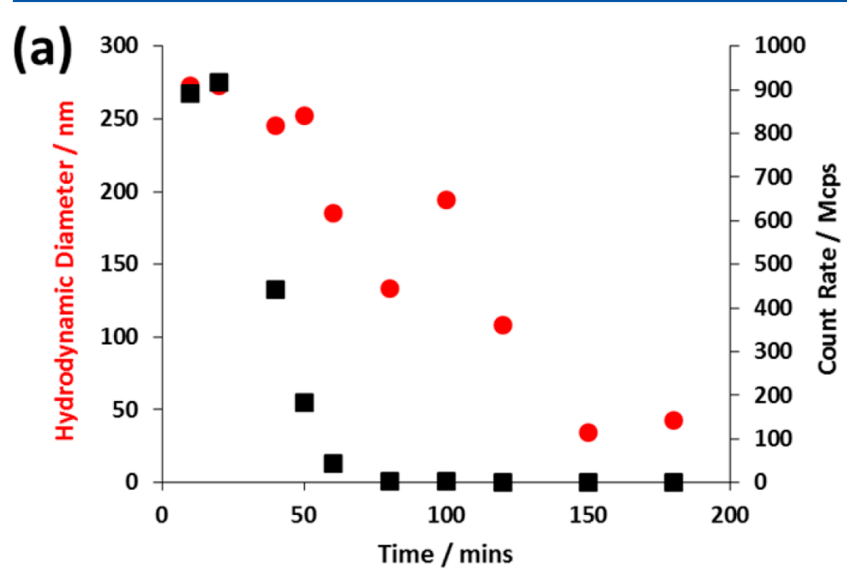

(b)

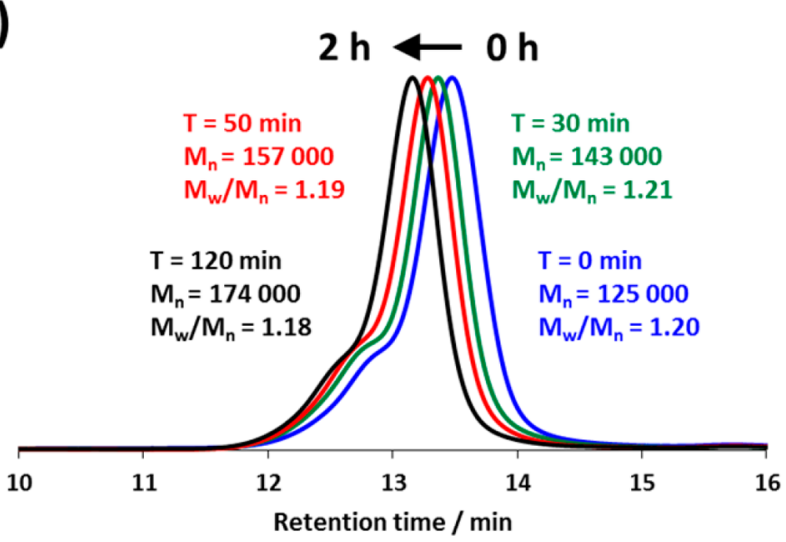

Figure 5. (a) Gradual reduction in particle size and derived count rate observed during the deprotection of $\mathrm{PGMA}_{39}-\mathrm{PIPGMA}_{1000}$ nanoparticles under the conditions described in Figure 4. (b) DMF GPC curves indicating the apparent increase in $M_{\mathrm{n}}$ and reduction in $M_{\mathrm{w}} / M_{\mathrm{n}}$ during the acid-catalyzed deprotection of $\mathrm{PGMA}_{39}-\mathrm{PIPGMA}_{1000}$.

The disappearance of the pendent methyl proton signals assigned to the IPGMA residues at 1.55 and $1.62 \mathrm{ppm}$ relative to the methacrylic copolymer backbone proton signals at $0.93-$ $1.43 \mathrm{ppm}$ in the ${ }^{1} \mathrm{H}$ NMR spectra allowed the extent of hydrolysis to be determined during the course of the acetal deprotection reaction. This analysis confirmed that more than $98 \%$ of the acetal groups were removed within $2 \mathrm{~h}$ at $70{ }^{\circ} \mathrm{C}$. As expected, the initially turbid dispersion gradually became less opaque and eventually became transparent as water-soluble GMA-rich copolymer chains (and ultimately PGMA homopolymer) were formed toward the end of the reaction. Surprisingly, DMF GPC analysis of the initial $\mathrm{PGMA}_{39}-$ PIPGMA $_{1000}$ diblock copolymer, intermediate copolymers, and final PGMA ${ }_{1039}$ homopolymer indicated an apparent increase in $M_{n}$ during acid deprotection. This is clearly an experimental artifact because the GMA repeat unit $\left(160 \mathrm{~g} \mathrm{~mol}^{-1}\right)$ is less massive than the IPGMA repeat unit $\left(200 \mathrm{~g} \mathrm{~mol}^{-1}\right)$. Presumably, DMF is a significantly better solvent for the PGMA chains (which hence occupy a larger hydrodynamic volume) than for the PIPGMA chains. It is perhaps also noteworthy that the molecular weight distribution remains essentially unchanged after deprotection, which confirms that no chain scission or cross-linking of the (co)polymer chains occurred under the hydrolysis conditions. Finally, DLS enabled the nanoparticle dissolution process to be conveniently monitored. The initial intensity-average diameter of $270 \mathrm{~nm}$ was reduced to just $30 \mathrm{~nm}$ within $150 \mathrm{~min}$ at $70^{\circ} \mathrm{C}$, while the scattered light intensity (or derived count rate) was reduced by more than two orders of magnitude over this time period. Moreover, the DLS polydispersities exceeded 0.50 after 120 min, which approximately corresponds to the time at which a significant reduction in solution turbidity is observed. Clearly, the size data shown here are rather noisy compared to the scattered light intensity (derived count rate), which most likely indicates the formation of transient, weakly scattering hydrogen-bonded complexes in aqueous solution. Overall, these observations are consistent with complete dissolution of the $\mathrm{PGMA}_{39}-\mathrm{PIPGMA}_{1000}$ diblock copolymer nanoparticles to afford molecularly-dissolved PGMA 1039 homopolymer chains.

Deprotection of the IPGMA residues was also examined under milder conditions. A $20 \% \mathrm{w} / \mathrm{w}$ aqueous dispersion of $\mathrm{PGMA}_{39}-\mathrm{PIPGMA}_{1000}$ nanoparticles was adjusted to $\mathrm{pH} 2$ using $\mathrm{HCl}$ and heated to $70{ }^{\circ} \mathrm{C}$. As expected, the rate of acid hydrolysis was significantly slower, but nevertheless 93\% deprotection was achieved within $10 \mathrm{~h}$ (see Figure 6). This presents a facile deprotection method for such polymers where the milder reaction conditions can be utilized at the expense of longer reaction times.

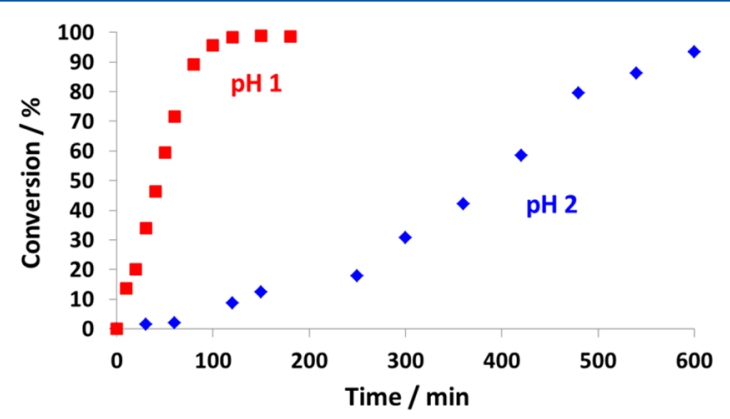

Figure 6. Conversion against time curves determined for the acid hydrolysis of a $20 \% \mathrm{w} / \mathrm{w}$ aqueous dispersion of $\mathrm{PGMA}_{39}-\mathrm{PIPGMA}_{1000}$ nanoparticles at $70{ }^{\circ} \mathrm{C}$ by ${ }^{1} \mathrm{H}$ NMR spectroscopy: (a) at $\mathrm{pH} 1$ (red squares) and $\mathrm{pH} 2$ (blue diamonds).

One-Pot Polymerization and Deprotection Protocol. Given that the RAFT aqueous emulsion polymerization and subsequent acid hydrolysis are both performed in aqueous solution at $70{ }^{\circ} \mathrm{C}$, the feasibility of developing a convenient one-pot polymerization and deprotection route to high molecular weight PGMA homopolymers was examined, as outlined in Figure 7. Thus, IPGMA was polymerized using the same PGMA $_{39}$ macro-CTA targeting a DP of 1000 for the PIPGMA. After $6 \mathrm{~h}$, an aliquot of the resulting turbid dispersion was extracted for analysis by ${ }^{1} \mathrm{H}$ NMR and DLS. The former technique indicated more than $99 \%$ conversion, and the latter suggested the presence of relatively uniform nanoparticles (338 $\mathrm{nm}$, polydispersity $=0.053)$. DMF GPC analysis indicated an $M_{\mathrm{n}}$ of 128000 and an $M_{\mathrm{w}} / M_{\mathrm{n}}$ of 1.37 , which indicates a somewhat broader molecular weight distribution than that reported in Table 1 (see entry 11) but still suggests reasonable RAFT control. This hot $20 \% \mathrm{w} / \mathrm{w}$ aqueous dispersion was then exposed to air and immediately adjusted to $\mathrm{pH} 1$ using $\mathrm{HCl}$. The reaction temperature was maintained at $70{ }^{\circ} \mathrm{C}$ for a further 
<smiles>C=C(C)C(=O)OC1CC(C)(OC(C)(C)C)OC1C(=O)OCC(O)COC(=O)C(C)(CC(C)(C)C)C(C)(C)CC(C)(C)C(=O)OCC1COC(C)(C)O1</smiles>
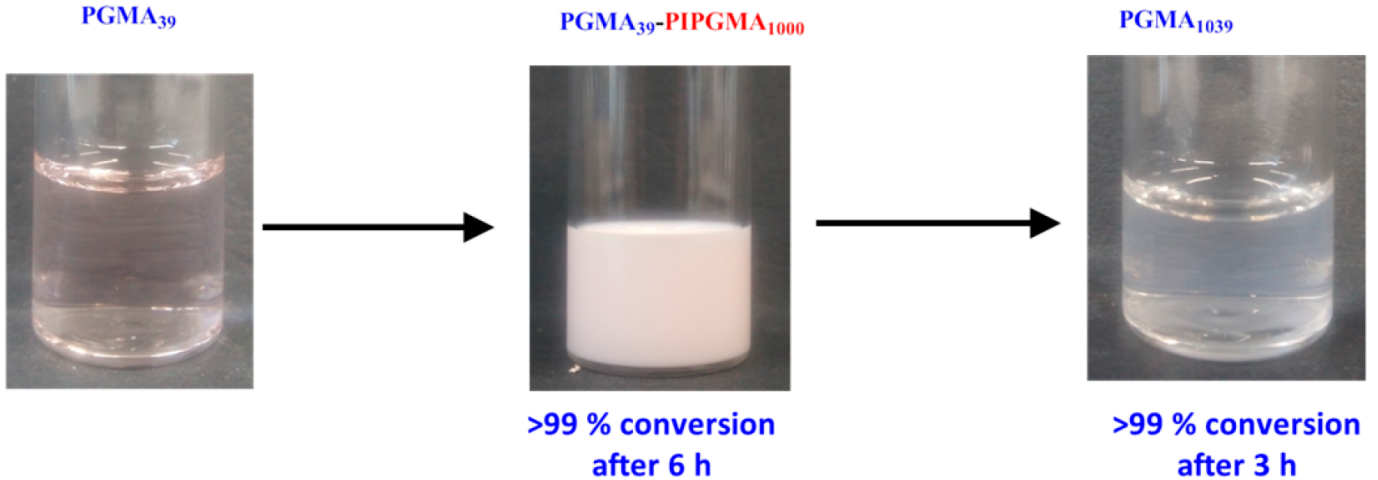

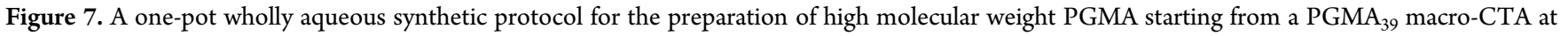
$20 \% \mathrm{w} / \mathrm{w}$ solids. First, RAFT aqueous emulsion polymerization of IPGMA is conducted at $70{ }^{\circ} \mathrm{C}$ to produce $\mathrm{PGMA}_{39}-\mathrm{PIPGMA}_{1000}$ nanoparticles at $\mathrm{pH} 4$, and then acid hydrolysis of the IPGMA residues is performed at the same temperature at $\mathrm{pH} 1$. The latter deprotection reaction leads to nanoparticle dissolution and the formation of a transparent aqueous solution comprising water-soluble PGMA $_{1039}$ homopolymer chains.

$3 \mathrm{~h}$ before taking an aliquot from the resulting transparent solution for analysis. ${ }^{1} \mathrm{H}$ NMR spectroscopy indicated more than $99 \%$ acetal deprotection, while both DLS studies and visual inspection confirmed loss of the original nanoparticles (see Figures 5a and 7, respectively). Finally, DMF GPC analysis of the final water-soluble $\mathrm{PGMA}_{1039}$ homopolymer obtained after an overall reaction time of $9 \mathrm{~h}$ at $70{ }^{\circ} \mathrm{C}$ had an apparent $M_{\mathrm{n}}$ of 154000 and an $M_{\mathrm{w}} / M_{\mathrm{n}}$ of 1.42 .

Advantages over Conventional Solution Polymerization. As described above, a wholly aqueous two-step onepot synthetic route to high molecular weight water-soluble PGMA has been developed. At this point, it is pertinent to ask whether this strategy offers any useful advantage(s) over the RAFT aqueous solution polymerization of GMA. Thus, the RAFT aqueous solution polymerization of GMA was conducted using the same GMA concentration $(16 \% \mathrm{w} / \mathrm{w}$ solids) as that achieved after acid hydrolysis of the $\mathrm{PGMA}_{39}-$ PIPGMA $_{1000}$ nanoparticles. To circumvent its limited water solubility, the CPDB RAFT agent was first dissolved in GMA monomer prior to addition of water and ACVA to make up the initial reaction solution. Aliquots were periodically taken for ${ }^{1} \mathrm{H}$ NMR and DMF GPC analysis to determine the kinetics of GMA polymerization and hence enable a direct comparison to be made with the overall time scale required for the two-step one-pot protocol utilizing the precursor $\mathrm{PGMA}_{39}-\mathrm{PIPGMA}_{1000}$ nanoparticles (see Figure 8).

The RAFT solution polymerization of GMA (targeting $\mathrm{PGMA}_{1000}$ ) proceeded to $81 \%$ conversion within $5 \mathrm{~h}$ at $70^{\circ} \mathrm{C}$, whereas the RAFT emulsion polymerization of IPGMA (targeting PGMA $_{39}-$ PIPGMA $_{1000}$ ) attained 97\% conversion within $2 \mathrm{~h}$ at the same temperature. It is well-known that emulsion polymerizations typically proceed significantly faster than the equivalent solution polymerization. ${ }^{80,91}$ This rate acceleration is attributed to compartmentalization, which reduces the instantaneous number of propagating polymer

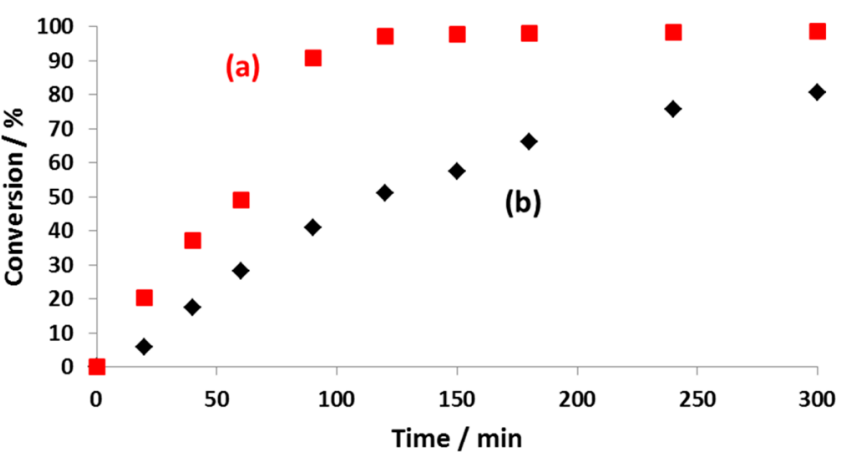

Figure 8. Conversion vs time plots obtained for (a) $\mathrm{PGMA}_{39}-$ PIPGMA $_{1000}$ nanoparticles prepared by RAFT aqueous emulsion polymerization of IPGMA (red squares) and (b) PGMA 1000 prepared via RAFT aqueous solution polymerization of GMA (black diamonds). Both syntheses were conducted at $70{ }^{\circ} \mathrm{C}$ at identical molar concentrations of monomer (either IPGMA or GMA); this corresponds to $16 \% \mathrm{w} / \mathrm{w}$ solids for the $\mathrm{PGMA}_{1000}$ chains and $20 \%$ $\mathrm{w} / \mathrm{w}$ solids for the $\mathrm{PGMA}_{39}-\mathrm{PIPGMA}_{1000}$. The loss of the acetone protecting group during acid hydrolysis of the IPGMA residues in the latter synthesis accounts for the difference in solids content.

radicals per growing nanoparticle and hence lowers the rate of termination relative to that of propagation. ${ }^{74,75}$ This homopolymer has an $M_{\mathrm{w}} / M_{\mathrm{n}}$ of 1.27 at $81 \%$ conversion (see Figure S6), which is somewhat higher than that achieved for the final $\mathrm{PGMA}_{1039}$ homopolymer obtained via the RAFT aqueous emulsion polymerization of IPGMA $\left(M_{\mathrm{w}} / M_{\mathrm{n}}=1.20\right.$ at $97 \%$ conversion). Importantly, the overall time scale required for the synthesis of $\mathrm{PGMA}_{1039}$ chains using the two-step one-pot synthesis protocol is significantly shorter than that required for the RAFT aqueous solution polymerization of GMA. Assuming that first-order rate kinetics holds for this solution polymerization (which is the best case scenario), a further $5.5 \mathrm{~h}$ at 70 ${ }^{\circ} \mathrm{C}$ would be required to achieve $97 \%$ conversion. Thus, it is 


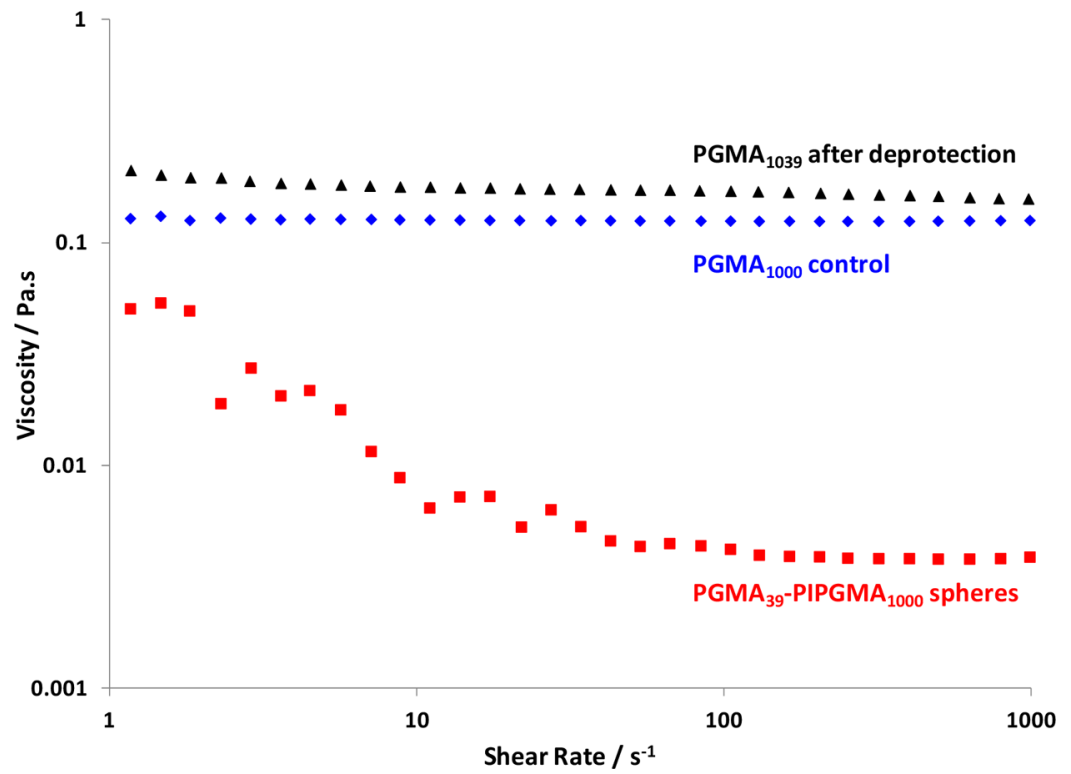

Figure 9. Viscosity vs. shear rate curves obtained for: (a) a $16 \% \mathrm{w} / \mathrm{w}$ aqueous solution of PGMA $_{1000}$ prepared via RAFT solution polymerization of GMA (blue diamonds); (b) a $20 \% \mathrm{w} / \mathrm{w}$ aqueous dispersion of $\mathrm{PGMA}_{39}-\mathrm{PIPGMA}_{1000}$ nanoparticles prepared via RAFT emulsion polymerization of IPGMA (red squares); and (c) a $16 \% \mathrm{w} / \mathrm{w}$ aqueous solution of $\mathrm{PGMA}_{1039}$ obtained after acid hydrolysis of a $20 \% \mathrm{w} / \mathrm{w}$ aqueous dispersion of $\mathrm{PGMA}_{39}-\mathrm{PIPGMA}_{1000}$ nanoparticles (black triangles). Rheological measurements were performed at $20^{\circ} \mathrm{C}$, and the differing solids concentrations correspond to approximately equimolar polymer concentrations.

clear that significantly higher final monomer conversions can be achieved using the former route within shorter overall reaction times.

Finally, rheological studies were performed to compare the viscosity of the aqueous solution of $\mathrm{PGMA}_{1000}$ to that of the aqueous dispersion of PGMA $_{39}-$ PIPGMA $_{1000}$ nanoparticles. In addition, the final water-soluble $\mathrm{PGMA}_{1039}$ homopolymer obtained after acid hydrolysis of the PGMA $_{39}-$ PIPGMA $_{1000}$ nanoparticles was also examined (see Figure 9).

The $20 \% \mathrm{w} / \mathrm{w}$ aqueous dispersion of PGMA $_{39}-$ PIPGMA $_{1000}$ nanoparticles exhibits a significantly lower viscosity than either of the two PGMA homopolymer solutions across the entire range of shear rates investigated $\left(10^{1}-10^{3} \mathrm{~s}^{-1}\right)$. Interestingly, an approximately Newtonian response is displayed by both these water-soluble homopolymers under these conditions, whereas shear-thinning behavior might have been expected. ${ }^{92,93}$ This could be simply because the range of shear rates examined in the present study is too narrow. Alternatively, it may indicate extensive interchain interactions (e.g., hydrogen bonding). In addition, the upturn observed at low shear rates for the $\mathrm{PGMA}_{39}-\mathrm{PIPGMA}_{1000}$ dispersion suggests weakly interacting nanoparticles. In summary, the one-pot synthesis of high molecular weight water-soluble PGMA via precursor PGMAPIPGMA nanoparticles can be conducted with faster kinetics, higher final monomer conversions, and lower viscosities than those achieved during the RAFT aqueous solution polymerization of GMA. This study provides a further example of the advantages offered by PISA formulations compared to conventional polymer syntheses conducted in homogeneous solution.

\section{CONCLUSIONS}

RAFT emulsion polymerization of IPGMA at $70{ }^{\circ} \mathrm{C}$ affords well-defined PGMA $_{39}-$ PIPGMA $_{x}$ diblock copolymer spherical nanoparticles at $20 \% \mathrm{w} / \mathrm{w}$ solids. High final monomer conversions (at least 97\%) could be reproducibly obtained when targeting PIPGMA block DPs up to 1000. A monotonic increase in both $M_{\mathrm{n}}$ and mean particle diameter was observed up to this critical value, with relatively low dispersities $\left(M_{\mathrm{w}} / M_{\mathrm{n}}\right.$ $<1.29$ ) being maintained. However, irreproducible results were obtained when targeting DPs of 1500 or 2000, so a target DP of 1000 appears to represent an upper limit, at least for this specific PISA formulation. Acid hydrolysis of the aqueous dispersion of $\mathrm{PGMA}_{39}-\mathrm{PIPGMA}_{1000}$ nanoparticles at $70{ }^{\circ} \mathrm{C}$ converts almost all $(>98 \%)$ of the hydrophobic IPGMA residues into hydrophilic GMA residues within $2 \mathrm{~h}$ at $\mathrm{pH} 1$. This leads to nanoparticle dissolution and the formation of an aqueous solution of $\mathrm{PGMA}_{1039}$ homopolymer.

Furthermore, a one-pot protocol was optimized whereby a highly viscous aqueous solution of $\mathrm{PGMA}_{1039}$ can be prepared at $20 \% \mathrm{w} / \mathrm{w}$ solids within $9 \mathrm{~h}$ from PGMA $_{39}-$ PIPGMA $_{1000}$ nanoparticles, which act as a low-viscosity precursor. Importantly, the relatively fast kinetics achieved during the RAFT emulsion polymerization of IPGMA means that the overall time scale for this one-pot synthesis is significantly shorter than that required for the synthesis of $\mathrm{PGMA}_{1039}$ via RAFT aqueous solution polymerization, despite the requirement for post-polymerization deprotection of the IPGMA residues. Moreover, the viscosity of an aqueous dispersion of PGMA $_{39}-$ PIPGMA $_{1000}$ nanoparticles at $20 \% \mathrm{w} / \mathrm{w}$ solids is significantly lower than that of PGMA $_{1000}$ prepared via RAFT aqueous solution polymerization. In summary, we report a new wholly aqueous synthetic route to relatively high molecular weight PGMA via RAFT aqueous emulsion polymerization that offers significant advantages in terms of both overall kinetics and lower viscosity compared to the RAFT aqueous solution polymerization of GMA. 


\section{ASSOCIATED CONTENT}

\section{S Supporting Information}

The Supporting Information is available free of charge on the ACS Publications website at DOI: 10.1021/acs.macromol.8b00294.

Figures S1-S6 (PDF)

\section{AUTHOR INFORMATION}

\section{Corresponding Author}

*E-mail s.p.armes@shef.ac.uk (S.P.A.).

ORCID

Steven P. Armes: 0000-0002-8289-6351

Notes

The authors declare no competing financial interest.

\section{ACKNOWLEDGMENTS}

GEO Specialty Chemicals (Hythe, UK) is thanked for supplying the GMA and IPGMA monomers and also for part-funding an EPSRC CDT PhD studentship for C.P.J. (EP/ L016281). S.P.A. is the recipient of a five-year ERC Advanced Investigator grant (PISA 320372).

\section{REFERENCES}

(1) Ginovart, M.; López, D.; Giró, A.; Silbert, M. Flocculation in brewing yeasts: A computer simulation study. BioSystems 2006, 83, 51.

(2) Zhang, D.; Thundat, T.; Narain, R. Flocculation and Dewatering of Mature Fine Tailings Using Temperature-Responsive Cationic Polymers. Langmuir 2017, 33, 5900.

(3) Mori, T.; Tsubaki, J.; O'Shea, J.-P.; Franks, G. V. Hydrostatic pressure measurement for evaluation of particle dispersion and flocculation in slurries containing temperature responsive polymers. Chem. Eng. Sci. 2013, 85, 38.

(4) Ng, W. S.; Sonsie, R.; Forbes, E.; Franks, G. V. Flocculation/ flotation of hematite fines with anionic temperature-responsive polymer acting as a selective flocculant and collector. Miner. Eng. 2015, 77, 64.

(5) Brostow, W.; Hagg Loblund, H.; Pal, S.; Singh, R. Polymeric flocculants for wastewater and industrial effluent treatment. J. Mater. Educ. 2009, 31, 157.

(6) Gregory, J. In Chemistry and Technology of Water-Soluble Polymers; Finch, C. A., Ed.; Springer: Boston, MA, 1983; p 307.

(7) Lee, C. S.; Robinson, J.; Chong, M. F. A review on application of flocculants in wastewater treatment. Process Saf. Environ. Prot. 2014, 92, 489.

(8) Thakur, V. K. In Cellulose-Based Graft Copolymers; Pal, S., Das, R. Ghorai, S., Eds.; CRC Press: Boca Raton, FL, 2015; p 301.

(9) Sakohara, S.; Nishikawa, K. Compaction of $\mathrm{TiO}_{2}$ suspension utilizing hydrophilic/hydrophobic transition of cationic thermosensitive polymers. J. Colloid Interface Sci. 2004, 278, 304.

(10) Abdallah/Qasaimeh, M. R.; Bani Hani, F.; Dawagreh, A. M. Neutral polyethylene oxide with a cofactor recommended for particle flocculation. Braz. J. Chem. Eng. 2011, 28, 467.

(11) Oveissi, F.; Sitter, T.; Fatehi, P. PDADMAC as a flocculant for lignosulfonate of NSSC pulping process. Biotechnol. Prog. 2016, 32, 686.

(12) Napper, D. H. Polymeric Stabilization of Colloidal Dispersions; Academic Press: New York, 1983.

(13) Fellows, C. M.; Doherty, W. O. S. Insights into Bridging Flocculation. Macromol. Symp. 2005, 231, 1.

(14) Hogg, R. Bridging Flocculation by Polymers. KONA 2013, 30, 3.

(15) Schulz, D. N.; Glass, J. E. Polymers as Rheology Modifiers; American Chemical Society: Washington, DC, 1991; Vol. 462.

(16) Miller, D.; Löffler, M. Rheological effects with a hydrophobically modified polymer. Colloids Surf., A 2006, 288, 165.
(17) Arai, N. Structural analysis of telechelic polymer solution using dissipative particle dynamics simulations. Mol. Simul. 2015, 41, 996.

(18) Ma, S. X.; Cooper, S. L. Shear Thickening in Aqueous Solutions of Hydrocarbon End-Capped Poly(ethylene oxide). Macromolecules 2001, 34, 3294.

(19) Glass, J. E. In Polymers in Aqueous Media; American Chemical Society: Washington, DC, 1989; Vol. 223.

(20) Du, Z.; Ren, B.; Chang, X.; Dong, R.; Peng, J.; Tong, Z. Aggregation and Rheology of an Azobenzene-Functionalized Hydrophobically Modified Ethoxylated Urethane in Aqueous Solution. Macromolecules 2016, 49, 4978.

(21) Glass, J. E. The role played by water-soluble polymers in paint performance. Part II: Chemical modeling studies. Journal of the Oil and Colour Chemists' Association 1976, 59, 86.

(22) Farrokhpay, S. A review of polymeric dispersant stabilisation of titania pigment. Adv. Colloid Interface Sci. 2009, 151, 24.

(23) Bothe, H.; Tretter, M.; Hagmann, P. US Patent US20140178595A1, 2015.

(24) Kim, J.; Liu, O.; Agresti, J.; Nguyen, A. T. US Patent US9714897B2, 2016.

(25) Holland, T. V.; Chang, F.; Haken, U.; Weinschenk, J. I. US Patent US9315669B2, 2016.

(26) Ratcliffe, L. P. D.; Ryan, A. J.; Armes, S. P. From a WaterImmiscible Monomer to Block Copolymer Nano-Objects via a OnePot RAFT Aqueous Dispersion Polymerization Formulation. Macromolecules 2013, 46, 769.

(27) Save, M.; Weaver, J. V. M; Armes, S. P.; McKenna, P. Atom Transfer Radical Polymerization of Hydroxy-Functional Methacrylates at Ambient Temperature: Comparison of Glycerol Monomethacrylate with 2-Hydroxypropyl Methacrylate. Macromolecules 2002, 35, 1152.

(28) Hassan, E.; Deshpande, P.; Claeyssens, F.; Rimmer, S.; MacNeil, $\mathrm{S}$. Amine functional hydrogels as selective substrates for corneal epithelialization. Acta Biomater. 2014, 10, 3029.

(29) Haigh, R.; Rimmer, S.; Fullwood, N. J. Synthesis and properties of amphiphilic networks. 1: the effect of hydration and polymer composition on the adhesion of immunoglobulin-G to poly(laurylmethacrylate-stat-glycerolmonomethacrylate-stat-ethylene-glycol-dimethacrylate) networks. Biomaterials 2000, 21, 735.

(30) Rimmer, S.; German, M. J.; Maughan, J.; Sun, Y.; Fullwood, N.; Ebdon, J.; MacNeil, S. Synthesis and properties of amphiphilic networks 3: preparation and characterization of block conetworks of poly(butyl methacrylate-block-(2,3 propandiol-1-methacrylate-statethandiol dimethacrylate)). Biomaterials 2005, 26, 2219.

(31) Haigh, R.; Fullwood, N.; Rimmer, S. Synthesis and properties of amphiphilic networks 2: a differential scanning calorimetric study of poly(dodecyl methacrylate-stat-2,3 propandiol-1-methacrylate-statethandiol dimethacrylate) networks and adhesion and spreading of dermal fibroblasts on these materials. Biomaterials 2002, 23, 3509.

(32) Patrucco, E.; Ouasti, S.; Vo, C. D.; De Leonardis, P.; Pollicino, A.; Armes, S. P.; Scandola, M.; Tirelli, N. Surface-Initiated ATRP Modification of Tissue Culture Substrates: Poly(glycerol monomethacrylate) as an Antifouling Surface. Biomacromolecules 2009, 10, 3130.

(33) Canton, I.; Warren, N. J.; Chahal, A.; Amps, K.; Wood, A.; Weightman, R.; Wang, E.; Moore, H.; Armes, S. P. Mucin-Inspired Thermoresponsive Synthetic Hydrogels Induce Stasis in Human Pluripotent Stem Cells and Human Embryos. ACS Cent. Sci. 2016, 2, 65.

(34) Yuan, J. J.; Armes, S. P.; Takabayashi, Y.; Prassides, K.; Leite, C. A. P.; Galembeck, F.; Lewis, A. L. Synthesis of Biocompatible Poly[2(methacryloyloxy)ethyl phosphorylcholine]-Coated Magnetite Nanoparticles. Langmuir 2006, 22, 10989.

(35) You, D. G.; Saravanakumar, G.; Son, S.; Han, H. S.; Heo, R.; Kim, K.; Kwon, I. C.; Lee, J. Y.; Park, J. H. Dextran sulfate-coated superparamagnetic iron oxide nanoparticles as a contrast agent for atherosclerosis imaging. Carbohydr. Polym. 2014, 101, 1225.

(36) Deng, R.; Derry, M. J.; Mable, C. J.; Ning, Y.; Armes, S. P. Using Dynamic Covalent Chemistry To Drive Morphological Transitions: 
Controlled Release of Encapsulated Nanoparticles from Block Copolymer Vesicles. J. Am. Chem. Soc. 2017, 139, 7616.

(37) Canning, S. L.; Smith, G. N.; Armes, S. P. A Critical Appraisal of RAFT-Mediated Polymerization-Induced Self-Assembly. Macromolecules 2016, 49, 1985.

(38) Warren, N. J.; Armes, S. P. Polymerization-Induced SelfAssembly of Block Copolymer Nano-objects via RAFT Aqueous Dispersion Polymerization. J. Am. Chem. Soc. 2014, 136, 10174.

(39) Derry, M. J.; Fielding, L. A.; Armes, S. P. Polymerizationinduced self-assembly of block copolymer nanoparticles via RAFT non-aqueous dispersion polymerization. Prog. Polym. Sci. 2016, 52, 1.

(40) Charleux, B.; Delaittre, G.; Rieger, J.; D’Agosto, F. Polymerization-Induced Self-Assembly: From Soluble Macromolecules to Block Copolymer Nano-Objects in One Step. Macromolecules 2012, 45, 6753.

(41) Cunningham, M. F. Controlled/living radical polymerization in aqueous dispersed systems. Prog. Polym. Sci. 2008, 33, 365.

(42) Rieger, J. Guidelines for the Synthesis of Block Copolymer Particles of Various Morphologies by RAFT Dispersion Polymerization. Macromol. Rapid Commun. 2015, 36, 1458.

(43) Zetterlund, P. B.; Thickett, S. C.; Perrier, S.; Bourgeat-Lami, E.; Lansalot, M. Controlled/Living Radical Polymerization in Dispersed Systems: An Update. Chem. Rev. 2015, 115, 9745.

(44) Lansalot, M.; Rieger, J.; D’Agosto, F. In Macromolecular Selfassembly; John Wiley \& Sons, Inc.: Hoboken, NJ, 2016; p 33.

(45) Rieger, J.; Zhang, W.; Stoffelbach, F.; Charleux, B. SurfactantFree RAFT Emulsion Polymerization Using Poly(N,N-dimethylacrylamide) Trithiocarbonate Macromolecular Chain Transfer Agents. Macromolecules 2010, 43, 6302.

(46) Truong, N. P.; Quinn, J. F.; Anastasaki, A.; Rolland, M.; Vu, M. N.; Haddleton, D. M.; Whittaker, M. R.; Davis, T. P. Surfactant-free RAFT emulsion polymerization using a novel biocompatible thermoresponsive polymer. Polym. Chem. 2017, 8, 1353.

(47) Zhang, W.; D’Agosto, F.; Dugas, P.-Y.; Rieger, J.; Charleux, B. RAFT-mediated one-pot aqueous emulsion polymerization of methyl methacrylate in the presence ofpoly(methacrylic acid-co-poly(ethylene oxide) methacrylate) trithiocarbonate macromolecular chain transfer agent. Polymer 2013, 54, 2011.

(48) Ferguson, C. J.; Hughes, R. J.; Pham, B. T. T.; Hawkett, B. S.; Gilbert, R. G.; Serelis, A. K.; Such, C. H. Effective ab Initio Emulsion Polymerization under RAFT Control. Macromolecules 2002, 35, 9243.

(49) Binauld, S.; Delafresnaye, L.; Charleux, B.; D’Agosto, F.; Lansalot, M. Emulsion Polymerization of Vinyl Acetate in the Presence of Different Hydrophilic Polymers Obtained by RAFT/MADIX. Macromolecules 2014, 47, 3461.

(50) Etchenausia, L.; Khoukh, A.; Deniau Lejeune, E.; Save, M. RAFT/MADIX emulsion copolymerization of vinyl acetate and $\mathrm{N}$ vinylcaprolactam: towards waterborne physically crosslinked thermoresponsive particles. Polym. Chem. 2017, 8, 2244.

(51) Poon, C. K.; Tang, O.; Chen, X.-M.; Kim, B.; Hartlieb, M.; Pollock, C. A.; Hawkett, B. S.; Perrier, S. Fluorescent Labeling and Biodistribution of Latex Nanoparticles Formed by Surfactant-Free RAFT Emulsion Polymerization. Macromol. Biosci. 2017, 17, 1600366.

(52) Byard, S. J.; Williams, M.; McKenzie, B. E.; Blanazs, A.; Armes, S. P. Preparation and Cross-Linking of All-Acrylamide Diblock Copolymer Nano-Objects via Polymerization-Induced Self-Assembly in Aqueous Solution. Macromolecules 2017, 50, 1482.

(53) Canning, S. L.; Cunningham, V. J.; Ratcliffe, L. P. D.; Armes, S. $\mathrm{P}$. Phenyl acrylate is a versatile monomer for the synthesis of acrylic diblock copolymer nano-objects via polymerization-induced selfassembly. Polym. Chem. 2017, 8, 4811.

(54) Wright, D. B.; Touve, M. A.; Adamiak, L.; Gianneschi, N. C. ROMPISA: Ring-Opening Metathesis Polymerization-Induced SelfAssembly. ACS Macro Lett. 2017, 6, 925.

(55) Lesage de la Haye, J.; Zhang, X.; Chaduc, I.; Brunel, F.; Lansalot, M.; D'Agosto, F. The Effect of Hydrophile Topology in RAFTMediated Polymerization-Induced Self-Assembly. Angew. Chem. 2016, $128,3803$.
(56) Tan, J.; Liu, D.; Bai, Y.; Huang, C.; Li, X.; He, J.; Xu, Q.; Zhang, L. Enzyme-Assisted Photoinitiated Polymerization-Induced SelfAssembly: An Oxygen-Tolerant Method for Preparing Block Copolymer Nano-Objects in Open Vessels and Multiwell Plates. Macromolecules 2017, 50, 5798.

(57) Zhang, W.; D’Agosto, F.; Boyron, O.; Rieger, J.; Charleux, B. Toward a Better Understanding of the Parameters that Lead to the Formation of Nonspherical Polystyrene Particles via RAFT-Mediated One-Pot Aqueous Emulsion Polymerization. Macromolecules 2012, 45, 4075.

(58) Boissé, S.; Rieger, J.; Pembouong, G.; Beaunier, P.; Charleux, B. Influence of the stirring speed and $\mathrm{CaCl} 2$ concentration on the nanoobject morphologies obtained via RAFT-mediated aqueous emulsion polymerization in the presence of a water-soluble macroRAFT agent. J. Polym. Sci., Part A: Polym. Chem. 2011, 49, 3346.

(59) Boisse, S.; Rieger, J.; Belal, K.; Di-Cicco, A.; Beaunier, P.; Li, M.H.; Charleux, B. Amphiphilic block copolymer nano-fibers via RAFTmediated polymerization in aqueous dispersed system. Chem. Commun. 2010, 46, 1950.

(60) Zhang, X.; Boissé, S.; Zhang, W.; Beaunier, P.; D’Agosto, F.; Rieger, J.; Charleux, B. Well-Defined Amphiphilic Block Copolymers and Nano-objects Formed in Situ via RAFT-Mediated Aqueous Emulsion Polymerization. Macromolecules 2011, 44, 4149.

(61) Cunningham, V. J.; Alswieleh, A. M.; Thompson, K. L.; Williams, M.; Leggett, G. J.; Armes, S. P.; Musa, O. M. Poly(glycerol monomethacrylate)-Poly(benzyl methacrylate) Diblock Copolymer Nanoparticles via RAFT Emulsion Polymerization: Synthesis, Characterization, and Interfacial Activity. Macromolecules 2014, 47, 5613.

(62) Truong, N. P.; Dussert, M. V.; Whittaker, M. R.; Quinn, J. F.; Davis, T. P. Rapid synthesis of ultrahigh molecular weight and low polydispersity polystyrene diblock copolymers by RAFT-mediated emulsion polymerization. Polym. Chem. 2015, 6, 3865.

(63) Chaduc, I.; Girod, M.; Antoine, R.; Charleux, B.; D’Agosto, F.; Lansalot, M. Batch Emulsion Polymerization Mediated by Poly(methacrylic acid) MacroRAFT Agents: One-Pot Synthesis of SelfStabilized Particles. Macromolecules 2012, 45, 5881.

(64) Chaduc, I.; Crepet, A.; Boyron, O.; Charleux, B.; D’Agosto, F.; Lansalot, M. Effect of the $\mathrm{pH}$ on the RAFT Polymerization of Acrylic Acid in Water. Application to the Synthesis of Poly(acrylic acid)Stabilized Polystyrene Particles by RAFT Emulsion Polymerization. Macromolecules 2013, 46, 6013.

(65) Manguian, M.; Save, M.; Charleux, B. Batch Emulsion Polymerization of Styrene Stabilized by a Hydrophilic Macro-RAFT Agent. Macromol. Rapid Commun. 2006, 27, 399.

(66) Fréal-Saison, S.; Save, M.; Bui, C.; Charleux, B.; Magnet, S. Emulsifier-Free Controlled Free-Radical Emulsion Polymerization of Styrene via RAFT Using Dibenzyltrithiocarbonate as a Chain Transfer Agent and Acrylic Acid as an Ionogenic Comonomer: Batch and Spontaneous Phase Inversion Processes. Macromolecules 2006, 39, 8632.

(67) Chaduc, I.; Reynaud, E.; Dumas, L.; Albertin, L.; D’Agosto, F.; Lansalot, M. From well-defined poly(N-acryloylmorpholine)-stabilized nanospheres to uniform mannuronan- and guluronan-decorated nanoparticles by RAFT polymerization-induced self-assembly. Polymer 2016, 106, 218.

(68) Read, E.; Guinaudeau, A.; Wilson, D. J.; Cadix, A.; Violleau, F.; Destarac, M. Low temperature RAFT/MADIX gel polymerisation: access to controlled ultra-high molar mass polyacrylamides. Polym. Chem. 2014, 5, 2202.

(69) Cunningham, V. J.; Derry, M. J.; Fielding, L. A.; Musa, O. M.; Armes, S. P. RAFT Aqueous Dispersion Polymerization of N-(2(Methacryloyloxy)ethyl)pyrrolidone: A Convenient Low Viscosity Route to High Molecular Weight Water-Soluble Copolymers. Macromolecules 2016, 49, 4520.

(70) Cho, M. S.; Yoon, K. J.; Song, B. K. Dispersion polymerization of acrylamide in aqueous solution of ammonium sulfate: Synthesis and characterization. J. Appl. Polym. Sci. 2002, 83, 1397.

(71) Anderson, D. R.; Frisque, A. J. US Patent US3624019A, 1971. 
(72) Scherer, M.; Kappel, C.; Mohr, N.; Fischer, K.; Heller, P.; Forst, R.; Depoix, F.; Bros, M.; Zentel, R. Functionalization of Active EsterBased Polymersomes for Enhanced Cell Uptake and StimuliResponsive Cargo Release. Biomacromolecules 2016, 17, 3305.

(73) McKenzie, A.; Hoskins, R.; Swift, T.; Grant, C.; Rimmer, S. Core (Polystyrene)-Shell [Poly(glycerol monomethacrylate)] Particles. ACS Appl. Mater. Interfaces 2017, 9, 7577.

(74) Smith, W. V.; Ewart, R. H. Kinetics of Emulsion Polymerization. J. Chem. Phys. 1948, 16, 592.

(75) Harkins, W. D. A General Theory of the Mechanism of Emulsion Polymerization1. J. Am. Chem. Soc. 1947, 69, 1428.

(76) Akpinar, B.; Fielding, L. A.; Cunningham, V. J.; Ning, Y.; Mykhaylyk, O. O.; Fowler, P. W.; Armes, S. P. Determining the Effective Density and Stabilizer Layer Thickness of Sterically Stabilized Nanoparticles. Macromolecules 2016, 49, 5160-5171.

(77) Blanazs, A.; Madsen, J.; Battaglia, G.; Ryan, A. J.; Armes, S. P. Mechanistic Insights for Block Copolymer Morphologies: How Do Worms Form Vesicles? J. Am. Chem. Soc. 2011, 133, 16581.

(78) Derry, M. J.; Fielding, L. A.; Warren, N. J.; Mable, C. J.; Smith, A. J.; Mykhaylyk, O. O.; Armes, S. P. In situ small-angle X-ray scattering studies of sterically-stabilized diblock copolymer nanoparticles formed during polymerization-induced self-assembly in nonpolar media. Chem. Sci. 2016, 7, 5078.

(79) Semsarilar, M.; Ladmiral, V.; Blanazs, A.; Armes, S. P. Anionic Polyelectrolyte-Stabilized Nanoparticles via RAFT Aqueous Dispersion Polymerization. Langmuir 2012, 28, 914.

(80) Jones, E. R.; Semsarilar, M.; Wyman, P.; Boerakker, M.; Armes, S. P. Addition of water to an alcoholic RAFT PISA formulation leads to faster kinetics but limits the evolution of copolymer morphology. Polym. Chem. 2016, 7, 851.

(81) Chaduc, I.; Zhang, W.; Rieger, J.; Lansalot, M.; D’Agosto, F.; Charleux, B. Amphiphilic Block Copolymers from a Direct and Onepot RAFT Synthesis in Water. Macromol. Rapid Commun. 2011, 32, 1270.

(82) Hatton, F. L.; Lovett, J. R.; Armes, S. P. Synthesis of welldefined epoxy-functional spherical nanoparticles by RAFT aqueous emulsion polymerization. Polym. Chem. 2017, 8, 4856.

(83) Lopez-Oliva, A. P.; Warren, N. J.; Rajkumar, A.; Mykhaylyk, O. O.; Derry, M. J.; Doncom, K. E. B.; Rymaruk, M. J.; Armes, S. P. Polydimethylsiloxane-Based Diblock Copolymer Nano-objects Prepared in Nonpolar Media via RAFT-Mediated Polymerization-Induced Self-Assembly. Macromolecules 2015, 48, 3547.

(84) Cunningham, V. J.; Ning, Y.; Armes, S. P.; Musa, O. M. Poly(N2-(methacryloyloxy)ethyl pyrrolidone)-poly(benzyl methacrylate) diblock copolymer nano-objects via RAFT alcoholic dispersion polymerisation in ethanol. Polymer 2016, 106, 189.

(85) Moad, G.; Rizzardo, E.; Thang, S. H. Living Radical Polymerization by the RAFT Process - A Third Update. Aust. J. Chem. 2012, 65, 985.

(86) Moad, G.; Rizzardo, E.; Thang, S. H. Living Radical Polymerization by the RAFT Process. Aust. J. Chem. 2005, 58, 379.

(87) Moad, G.; Rizzardo, E.; Thang, S. H. Living Radical Polymerization by the RAFT Process - A Second Update. Aust. J. Chem. 2009, 62, 1402.

(88) Clayden, J.; Greeves, N.; Warren, S. G. Organic Chemistry; Oxford University Press: New York, 2012.

(89) Hoogeveen, N. G.; Stuart, M. A. C.; Fleer, G. J.; Frank, W.; Arnold, M. Novel water-soluble block copolymers of dimethylaminoethyl methacrylate and dihydroxypropyl methacrylate. Macromol. Chem. Phys. 1996, 197, 2553.

(90) Yu, D. M.; Mapas, J. K. D.; Kim, H.; Choi, J.; Ribbe, A. E.; Rzayev, J.; Russell, T. P. Evaluation of the Interaction Parameter for Poly(solketal methacrylate)-block-polystyrene Copolymers. Macromolecules 2018, 51, 1031-1040.

(91) Odian, G. In Principles of Polymerization, 4th ed.; Wiley: Hoboken, NJ, 2004.

(92) Ryder, J. F.; Yeomans, J. M. Shear thinning in dilute polymer solutions. J. Chem. Phys. 2006, 125, 194906.
(93) Bird, R. B.; Armstrong, R. C.; Hassager, O. Dynamics of Polymeric Liquids, 2nd ed.; John Wiley and Sons Inc.: New York, 1987; Vol. 1. 